\title{
Lighting Features in Historical Buildings: Scientific Analysis of the Church of Saint Louis of the Frenchmen in Sevilla
}

\author{
Jose-Manuel Almodovar-Melendo ${ }^{1, *} \mathbb{}{ }^{10}$, Joseph-Maria Cabeza-Lainez ${ }^{1}$ \\ and Inmaculada Rodriguez-Cunill ${ }^{2}$ \\ 1 School of Architecture and the Faculty of East Asian Studies, University of Seville, \\ 41012 Sevilla, Spain; crowley@us.es \\ 2 Faculty of Fine Arts, University of Sevilla, 41003 Sevilla, Spain; irodrigu8@gmail.com \\ * Correspondence: jmalmodovar@us.es; Tel.: +34-954-556556
}

Received: 18 July 2018; Accepted: 14 September 2018; Published: 19 September 2018

\begin{abstract}
Heritage issues have increased significantly in recent years. However, they tend to remain in the cultural sphere and are often resistant to scientific analyses. If we have to deal with the contradictory matter of sustainability in design for ancient buildings, such hindrances appear frequently. A crucial aspect in Architecture has always been its capacity to dispose internal spaces and apertures in a manner that enhances the balance of light and thus provides attuned perception and well-being. Poor performance in that respect raised objections against the prestige of admirable works and famed artists. If we reject the absurd idea of accurately reproducing identical buildings in the same place repeatedly, how are we supposed to benefit from the said knowledge without the help of any objective design tools? It is easy to agree that at least we would need some scientific support to transmit such proper effects. Aware of the former notions, authors have developed a novel simulation software called DianaX, which is based on mathematical models and equations produced and expanded by Joseph Cabeza-Laïnez, from roughly 1990 to 2018. This non-commercial software deals with radiative exchanges in all kinds of surfaces (for instance domes, vaults, cylinders, hyperboloids and curves in general). It also includes direct sun in the simulations unlike most programs. Therefore, it is ideally suited for the analysis of heritage architecture and especially that which identifies with the Renaissance, baroque and neoclassical epochs. The case of temples from the baroque period resumes the conflict expressed in the first paragraph and the Jesuit Church of Saint Louis (1699-1731) is one of the most relevant examples of efficient illumination found in Mediterranean latitudes, having been recently restored. In this article, we would like to discuss the subtle and interesting implications of employing our simulation software for lighting in such a complex baroque temple. The methodology would be to identify the main energy sources within the church in order to construct a suitable model for simulation. Subsequently we apply the said software DianaX to such model and establish the most significant results trying to compare them with available on-site measurements. Finally, a strategy to enhance day-lighting and supplement it with other light sources in the church is proposed.
\end{abstract}

Keywords: daylighting; architectural simulation; monitoring; Saint Louis of the Frenchmen; iconography

\section{Introduction}

Famous buildings from the past and the present have brandished their excellence in the respect of lighting control. Their thresholds were praised from an artistic point of view for the way in which solar radiation penetrated their interiors [1]. It is said that these buildings scattered the light when it 
was excessive or augmented it if scarce. Inside their vaults the light itself has been termed by poets or architects as quaint, bland, dim, uplifting, ruthless or even monosyllabic. Consequently, knowledge of daylighting has interested many architectural theorists including Siegfried Giedion, Le Corbusier's colleague, who pointed out:

"It is light that induces the sensation of space. Space is annihilated by darkness. Light and space are indissolubly summoned." [2] (p. 445)

Even though architectural theoreticians have celebrated the excellence of daylighting in relevant buildings, they carried out very few assessments of such illumination. In fact, the architectural literature has usually shown a high degree of inaccuracy regarding its most revered buildings (Figures 1 and 2). Consequently, they have produced an undesired effect, the inability to preserve or transmit the benefits of daylighting in historic halls, thus provoking inadequacy of environmental measures and supplementary means of lighting.

We would agree that we require objective evaluation of performance in ancient buildings. However, such evaluation of lighting is difficult and cumbersome due to the unpredictable behaviour of visitors and personnel and the variability of weather conditions. Henceforth simulation is an appropriate tool to evaluate the potential of the building in sustainability terms, given that we take certain caveats into account [3].

Following such concern, we have been involved, for a number of years, in the development of a mathematical model to simulate the radiation or more specifically illumination in a physical or architectural medium. To this end, the authors expand a series of algorithms stemming from the algebra of configuration factors [4]. This mathematical model extends the radiation properties of diffuse sources to all kinds of luminous exitance from building surfaces irrespective of their shape (a significant novelty to our knowledge) and including the reflected component, even for curved geometries, for the first time in history. The surfaces are therefore treated as radiative emitters by virtue of the generalized law of the projected solid angle $[5,6]$. The concept of surface source allows for the inclusion of direct solar radiations since it is independent of the sky condition. The simulation of the aforementioned objectives can be fulfilled by entirely geometric or formal factors and thus appropriate to the architectural profession.

When we are discussing a radiant phenomenon in which a sufficiently diffuse energy is transmitted, we intend to know how the energy will be propagated or distributed so we can improve our architectural design with respect to such distribution. In this regard, illumination manifests itself through fields of a fundamentally vector nature [7]. Therefore, our main objective is to discern the behaviour of these fields in their unaltered state. On this topic, we have incorporated important contributions by Yamauchi [8], Moon and Spencer [9,10] among others.

Nevertheless, modifications of architectural features have the potential to alter substantially the field of study. In this regard, one of the main problems in environmental sciences applied to architecture has been to determine in which ways the existing physical fields are transformed due to buildings' features and towards which direction our design should be oriented in the search for a sounder transmission of climatic events [11]. In other words, how the design and architectural forms could be improved to achieve an optimal and coherent distribution of natural energies or at least of supplementary energy in the case of retrofit of heritage.

In this regard, the proposed mathematical model allows us to determine the illuminance vector at every point of the space under study and hence to immediately obtain the flux lines in the radiant field caused by any architecturally conceived form. This procedure has been validated in dozens of projects and hundreds of radiation measurements around the world [12-23], see Figure 3. Among them, we would like to present some random cases of the following: in Rome (Italy), the Church of Sant'Andrea by Bernini, Sant'Ivo by Borromini and the Pantheon. In Paris (France) the National Library by Henri Labrouste. In Kyoto (Japan), the Buddhist temple of Ryoanji. In Salvador (Brazil) the Church of Sao Bento, in India the temples of Ajanta and Modhera and in Korea the temple of Seokguram (Gyeongju). These field works have been completed roughly between 1996 and 2018. 


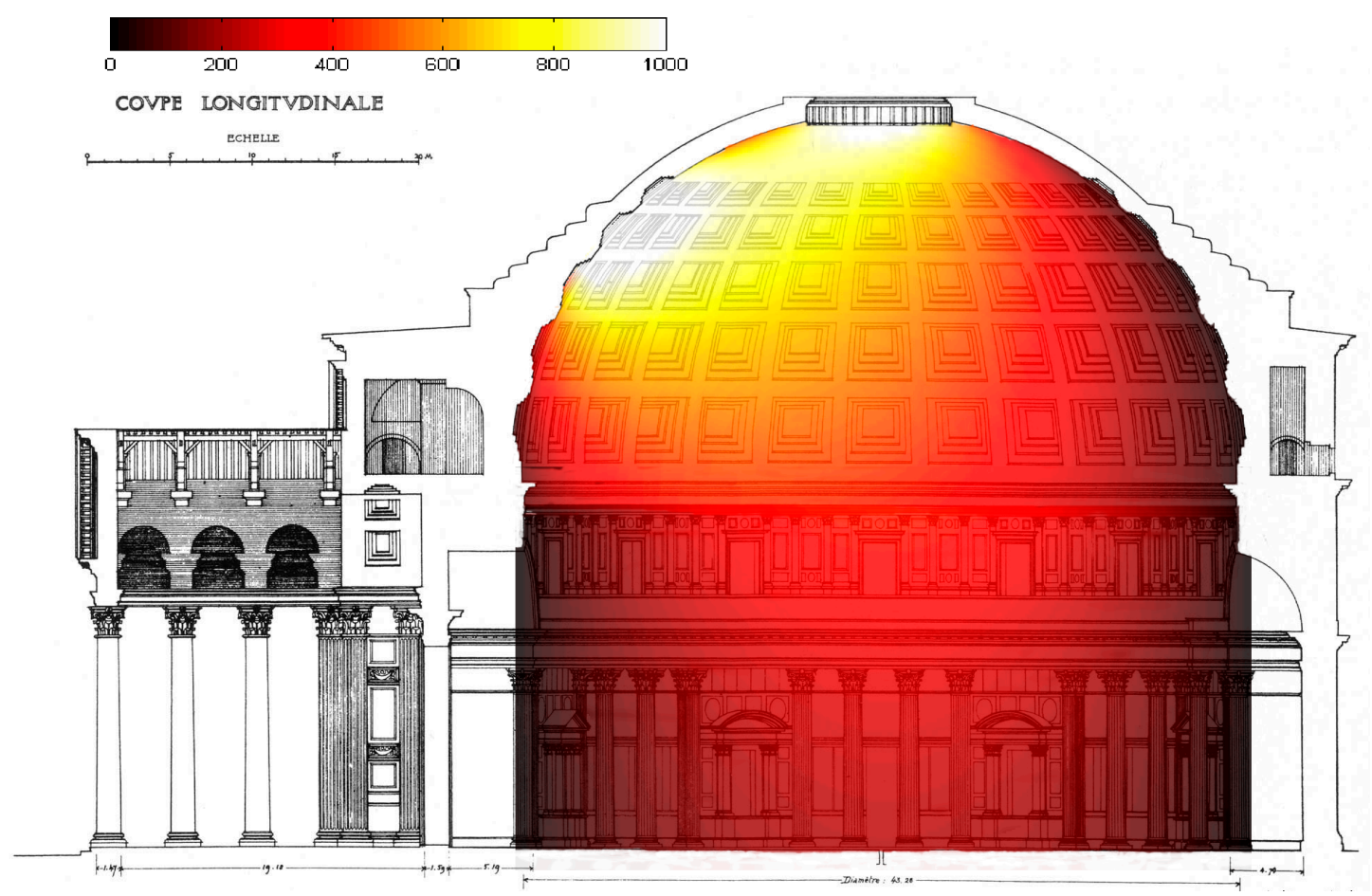

Figure 1. The Roman Pantheon, lighting simulation conducted and validated by Joseph Cabeza-Laïnez.

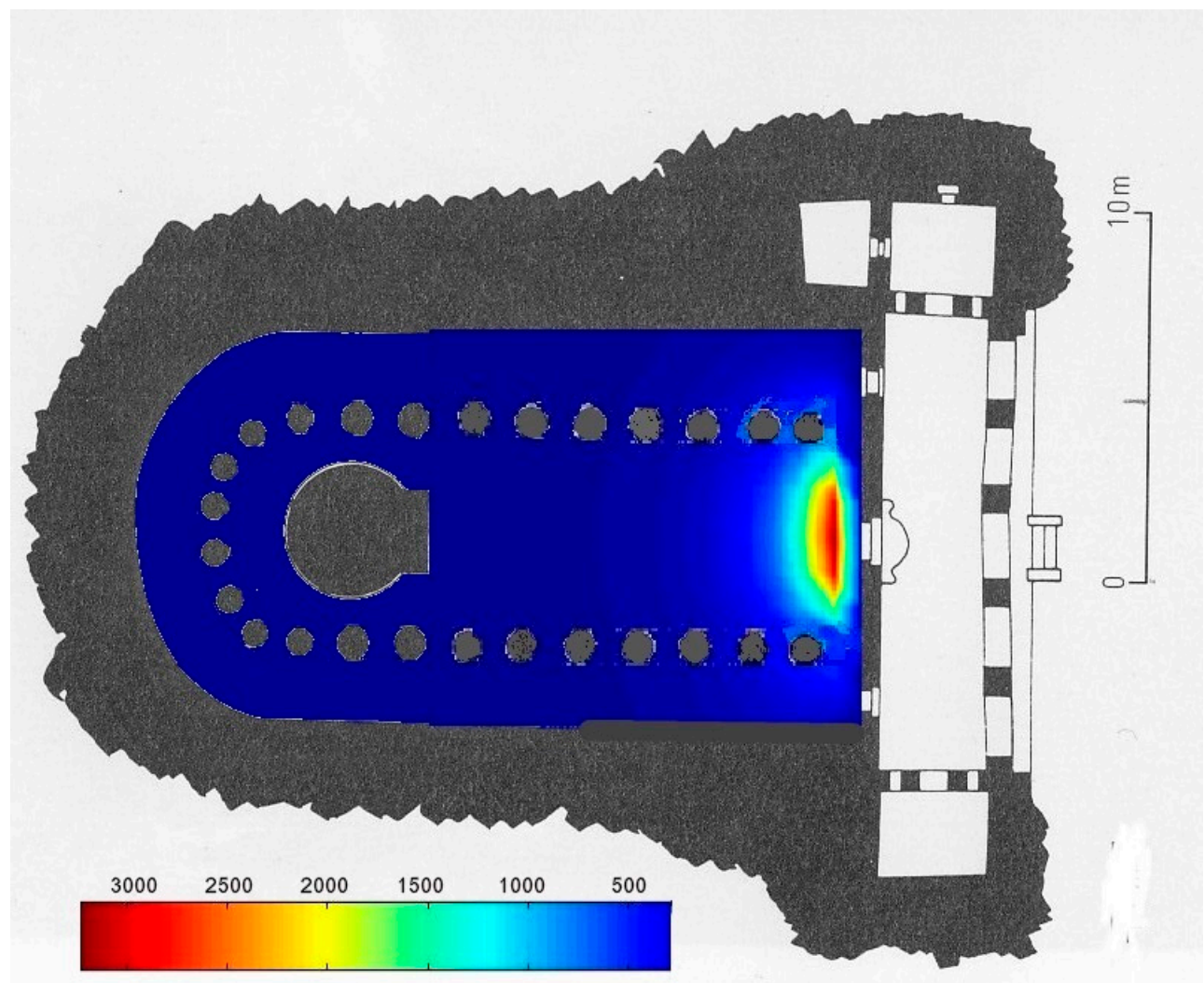

Figure 2. Plans and Views of Chaitya number 26 at Ajanta (India) showing illuminance levels. (3000-50 lux). Simulation conducted and validated by Joseph Cabeza-Laïnez.

In this manner, such remarkable spaces for Universal Architectural History have been thoroughly and painstakingly analysed and we ought to say that with the encouragement of no one. 

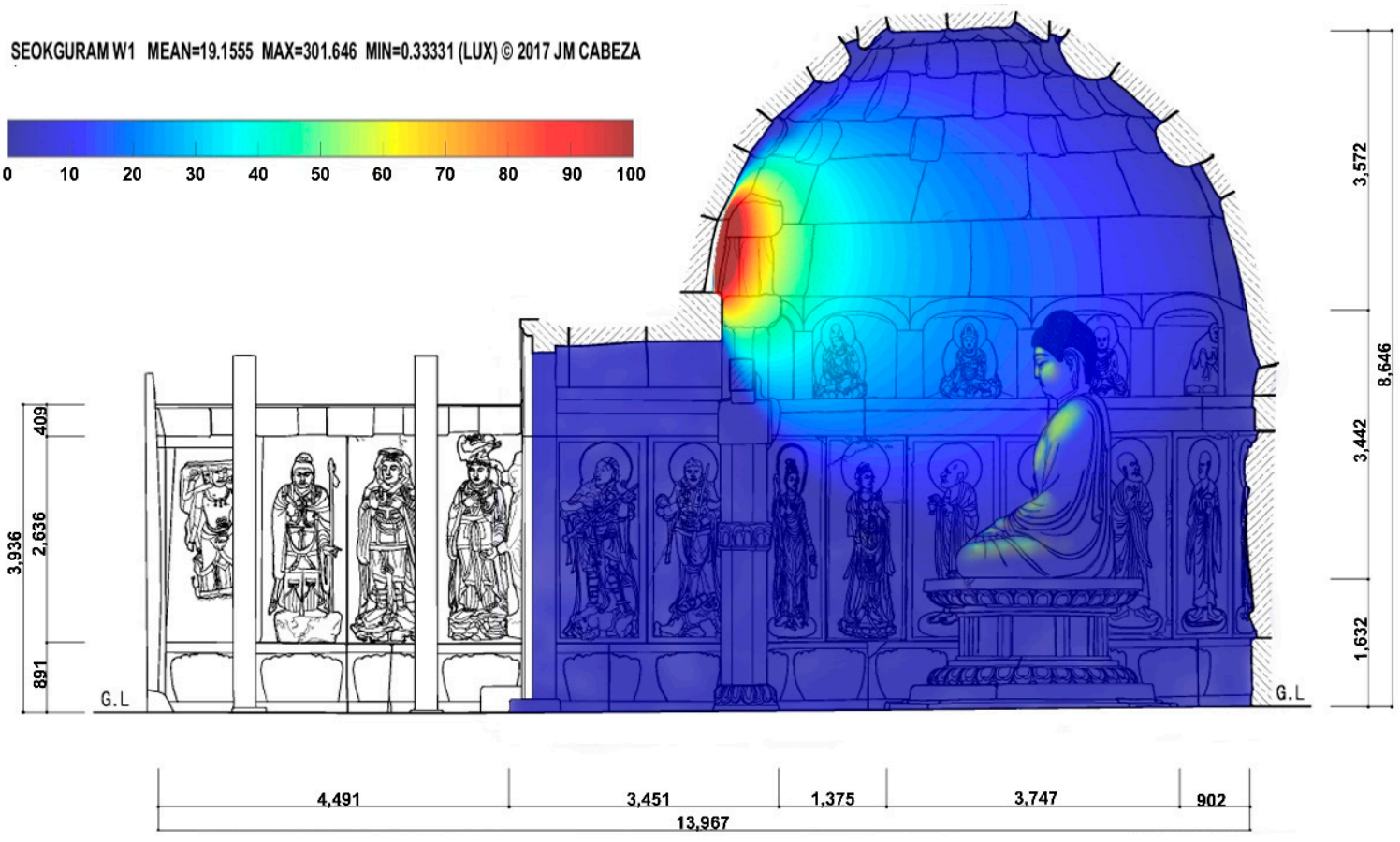

Figure 3. The Seokguram Buddha temple at Gyeongju (Korea). Simulation of a hypothetical aperture conducted and validated by Joseph Cabeza-Laïnez.

\section{A Brief Outline of the History of the Church}

The Church of Saint Louis lies in Sevilla in the southernmost point of Spain (latitude $37^{\circ} 22^{\prime} \mathrm{N}$ ), (Figure 4). It was erected by local builders between 1699 and 1731 under the guidance of Jesuit architects and hypothetically among them Angelo Italia. The building was so influential in the urban layout that the former King's Street, in which the church is located, changed its name to the current denomination of Saint Louis' Street.

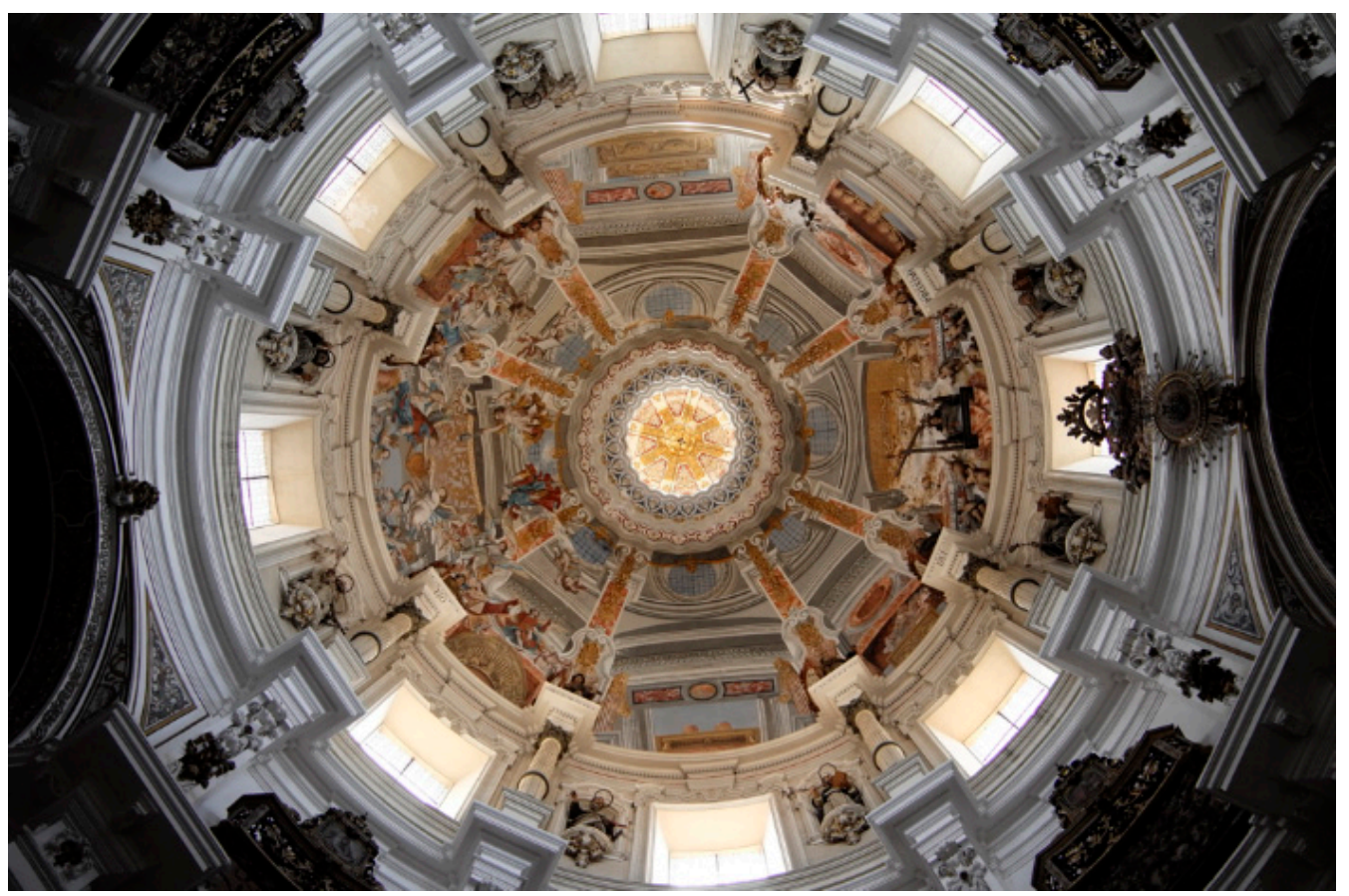

Figure 4. View of the Dome decorated with frescoes from the inside and the lantern and main eight windows. Source: Almodovar-Melendo. 
Despite the discussion on the authorship of the project, an important participation in the works of the famous Sevillian master Leonardo de Figueroa has been reported, albeit in collaboration with other artists. Its Greek-cross disposition is rare in Spain and probably relates to the Italian tradition showing a clear parallel with the church of S. Francesco Saverio (St. Francis Xavier) in Palermo (Sicily), where the Jesuit Angelo Italia was the chief architect. In fact, resemblances can be traced to other important religious constructions, featuring designs by Carlo Fontana, Bernini, Rainaldi or Borromini, like the church of Santa Maria in Monte Santo or Santa Agnese in Piazza Navona. The church has been considered as one of the most outstanding temples erected by the Society of Jesus of all times and comparable to the ancient wonders of antiquity as ziggurats et cetera [24].

This church is oriented according to the four cardinal points in a way that the main entrance is located to the east and the main altar to the west and, in this manner, revolves the usual Christian disposition where the main façade must face west. Many artworks manufactured by great masters of the Sevillian Baroque can be found in the interior of the church [25]. The altarpieces, which exhibit a great profusion of gilt surfaces and other glistening and reflective details, were mainly carved by Pedro Duque Cornejo and the author of the majority of the frescoes was Domingo Martinez. The iconographic program refers to relevant evangelizers and founders of the Society of Jesus like Xavier depicted in his arrival to the shores of Japan and Loyola. An altarpiece dedicated to Saint Stanislaus Kostka was carved in the south wall, while another dedicated to Saint Francis Borgia appears in the north side of the temple (Figure 5).

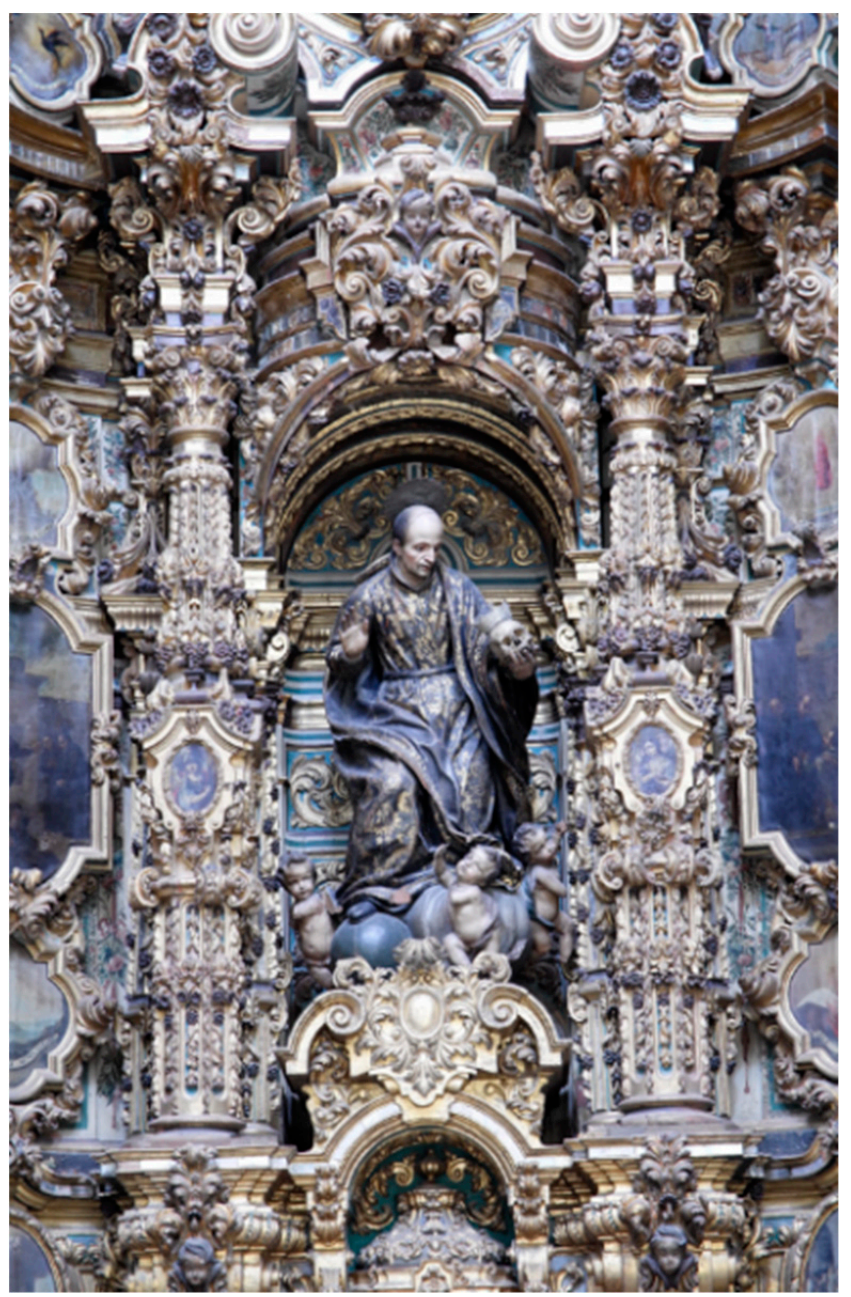

Figure 5. Altarpiece dedicated to Saint Francis Borgia, detail of the church. Source: Almodovar-Melendo. 
Referring to the girth and typology of the building, the width of the cupola is of $13.5 \mathrm{~m}$ and it rests on a drum $14.85 \mathrm{~m}$ high, that presents eight tall windows with a total area of 6.3 square meters each. It is interesting to notice that the ratio of glazing to lateral enveloping area is lesser than $10 \%$ and incomparable to modern buildings made of curtain walls or even fully glazed (Figure 6).

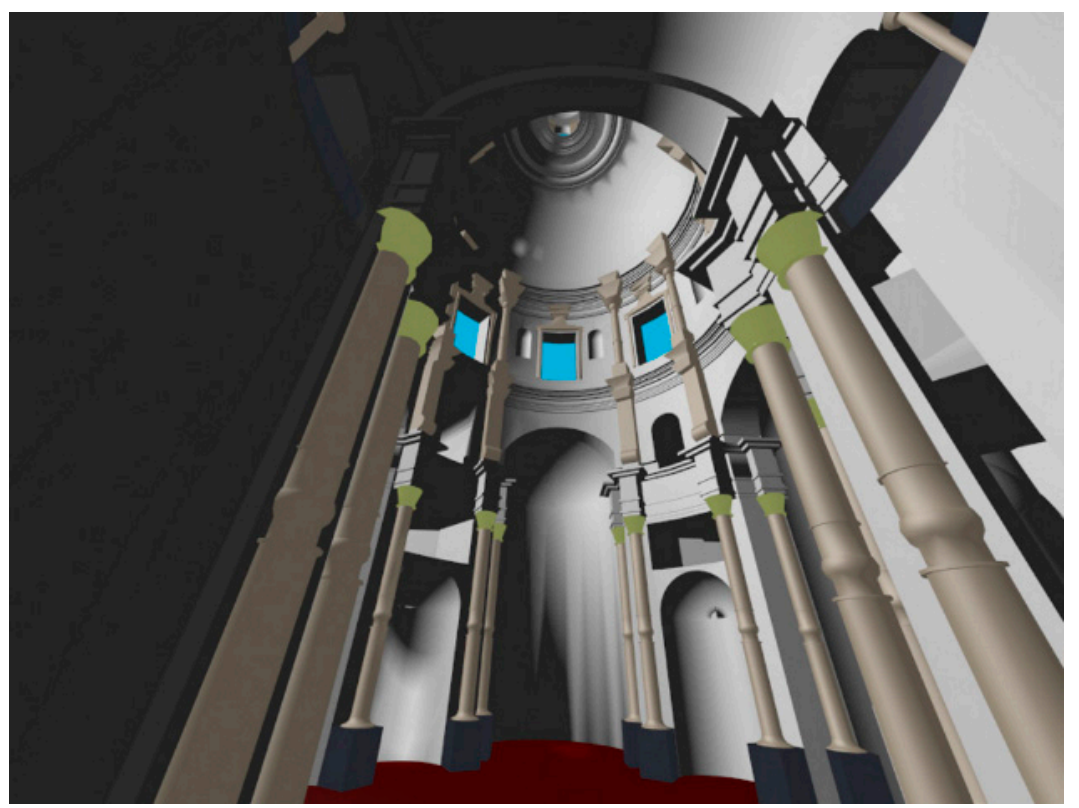

Figure 6. Virtual reality depiction of the central nave of the Church. Source: Gonzalo Pulido.

\section{Description of the Mathematical Model}

\subsection{Fundamentals}

A variety of mathematical models has been employed to determine the potential of the physical components at the nave of the church and to simulate its daylighting fields. The basic operations involve a configuration factor algebra newly developed by the authors. Another important innovation of the method proposed is that it incorporates both the direct and reflected component of light for curved surfaces, as we will discuss in more detail below. This procedure, a further advance of the research of Yamauchi and the American engineers H. Higbie and Levine [26], completes Lambert's corollary of reciprocity [27], representing a more generalized version of the form factors concomitant with those used in heat transfer for radiometric systems [28].

The model extends the radiation properties of diffuse sources to luminous exitance of all kinds of building surfaces that are subsequently considered as radiative emitters. Once the initial intensity of each surface is known and the primary shape of the exchangers is fixed, successive interchanges are obtained until a balance of the required accuracy is achieved.

The configuration factor is a dimensionless fraction (varying from zero to one) that originated in the work of J. Lambert (1760). It expresses the amount of radiant flux $E_{b}$ that arrives from a given surface to others directly exposed to the first, if both are perfectly diffuse emitters. It depends solely on the position, size and form of the given surfaces. Therefore, we could term it as geometrical and the corresponding domain of study of these matters is geometric optics [29]. Mathematically speaking, we can define it by the following integral equation whose terms appear in Figure 7.

$$
F_{12}=\frac{1}{A_{1}}\left[\int_{A_{2}} \int_{A_{1}} \frac{\cos \theta_{1} \cos \theta_{2}}{\pi r^{2}} d A_{1} d A_{2}\right],
$$

where $E_{b i}$ is the radiant power emitted by the corresponding surface 1 or 2 (lumen $\left./ \mathrm{m}^{2}\right) . A_{i}$ is the area of surface, $d A_{i}$ is the differential of area $\left(\mathrm{m}^{2}\right) ; r$ is the distance radio-vector $(\mathrm{m}) . \theta_{i}$ is the angle between 
radio-vector at differential element $i$ and the normal to the surface (radians), $d \Phi_{1-2}$ is the differential of radiant flux from surface 1 to 2 (lumen).

The previous expression states that radiant interchange for every given form depends on its shape and its relative position in the three-dimensional space. From the times of Lambert to our days, researchers and scientists in the fields of geometric optics and radiative transfer have sought to provide solutions to the canonical equation in the figure for a variety of forms [6]. This implies no minor feat, since the said equation leads, in most cases, to a quadruple integration and the fourth degree primitive of even simple mathematical expressions often entails lengthy calculations [4].

The configuration factors $F_{i j}$ possess the well-known property by virtue of which,

$$
\sum_{j=i}^{n} F_{i j}=1
$$

For any surface $A_{i}$ and this implies within an enclosure of $n$ surfaces,

$$
F_{11}+F_{12}+F_{13}+\ldots+F_{1 n}=1.0,
$$

If only planar surfaces are considered $F_{11}=0$ (a flat surface does not see itself). But in the particular case of baroque churches with many curved surfaces like spheres and cylinders, the factors with repeated sub-indexes tend to have values which have not been described in the literature in an exact formulation. Such is a significant part of the novelty and opportunity of our approach and simulation program, one of the main reasons behind this article.

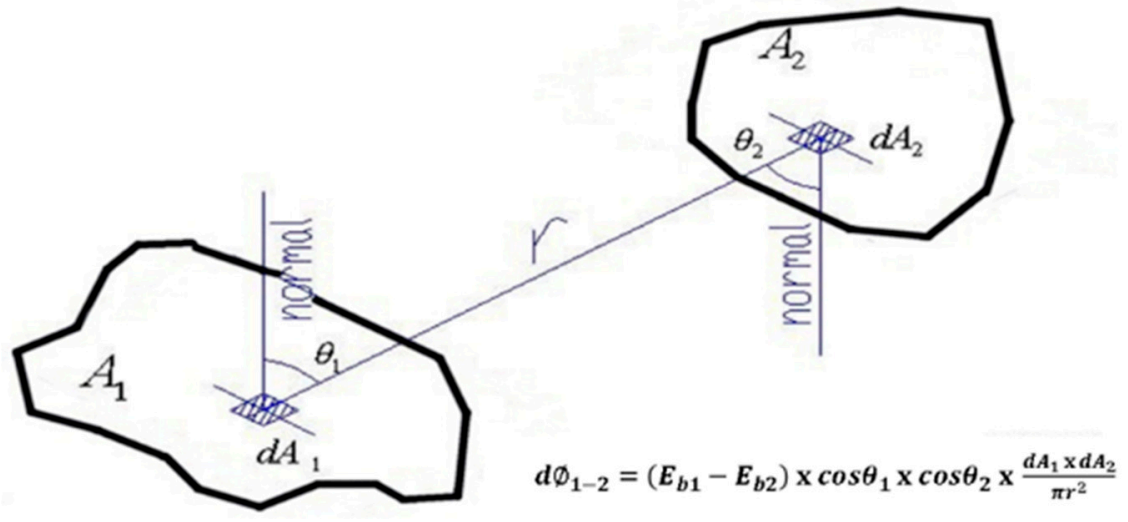

Figure 7. Equation parameters. Source: Joseph Cabeza-Laïnez.

The authors have devoted more than a decade of their careers to solve the former integral equation in an exact manner and the main outcome is that both the accuracy and speediness of computational time with these procedures are radically enhanced.

The second fundamental property of configuration factors is lack of symmetry. Since, due to Lambert's law, $A_{1} F_{12}=A_{2} F_{21}$ consequently, $F_{12} \neq F_{21}$, unless both surfaces have the same size.

The authors have established based on these two principle axioms a complete algebra for the first time in the literature that includes not only addition but also scalar product. We judge that to delve on this product exceeds the scope of the present article. Suffice to say that it permits the analysis of concatenated curved surfaces (previously untreated).

For the particular case of rectangular windows, if we are discussing their effects in the daylighting performance of a building, we should be utterly aware of how and where and especially under which conditions the light reaches the inner spaces. With this objective in mind, expressions for the configuration factor between rectangular inclined surfaces have been integrated at several angles to be used for daylighting simulation (Figure 8). 
The window is considered to be, a uniform diffuse luminous source (its luminance $L$ in lumen is constant for a given instant of time). As a result, we can obtain the following and more general expression for its illuminance $E$ (lumen $/ \mathrm{m}^{2}$ ):

$$
E=\frac{L}{2}\left[\begin{array}{c}
\frac{a \cos \varphi-y}{\sqrt{a^{2}+y^{2}-2 a y \cos \varphi}} \operatorname{arctg} \frac{b}{\sqrt{a^{2}+y^{2}-2 a y \cos \varphi}}+ \\
+\frac{b \cos \varphi}{\sqrt{b^{2}+y^{2} \sin ^{2} \varphi}} \operatorname{arctg} \frac{a \sqrt{b^{2}+y^{2} \sin ^{2} \varphi}}{b^{2}+y^{2}-a y \cos \varphi}+\operatorname{arctg} \frac{b}{y}
\end{array}\right],
$$

Angle $\varphi$ defines the relation with the normal to the considered work-plane. If $\varphi=90^{\circ}$, cosine is 0 and the expression equates the formula for vertical rectangles to a point-source.

$$
E=\frac{L}{2}\left[\operatorname{arctg} \frac{b}{y}-\frac{y}{\sqrt{a^{2}+y^{2}}} \operatorname{arctg} \frac{b}{\sqrt{a^{2}+y^{2}}}\right],
$$

The above expression (4) alters if we are trying to find the illuminance of the perpendicular surface; consequently, the solving equation would be in this case,

$$
E=\frac{L}{2}\left[\begin{array}{c}
\frac{a \sin \varphi}{\sqrt{a^{2}+y^{2}-2 a y \cos \varphi}} \operatorname{arctg} \frac{b}{\sqrt{a^{2}+y^{2}-2 a y \cos \varphi}}+ \\
+\frac{b \sin \varphi}{\sqrt{b^{2}+y^{2} \sin ^{2} \varphi}} \operatorname{arctg} \frac{a \sqrt{b^{2}+y^{2} \sin ^{2} \varphi}}{b^{2}+y^{2}-a y \cos \varphi}
\end{array}\right],
$$

It is easy to notice in this situation that if $\varphi=90^{\circ}$, this would give $\cos \varphi=0$ and $\sin \varphi=1$, substituting these values in the former equation:

$$
E=\frac{L}{2}\left[\frac{a}{\sqrt{a^{2}+y^{2}}} \operatorname{arctg} \frac{b}{\sqrt{a^{2}+y^{2}}}+\frac{b}{\sqrt{b^{2}+y^{2}}} \operatorname{arctg} \frac{a}{\sqrt{b^{2}+y^{2}}}\right],
$$

This expression represents the exchange between a horizontal rectangle and a point-source parallel surface.

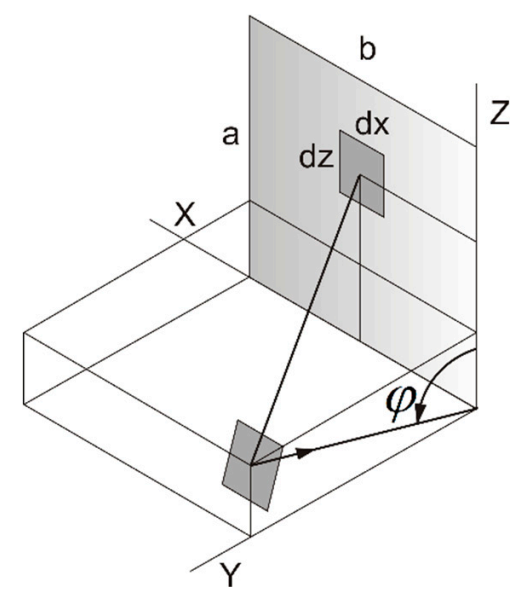

Figure 8. Configuration factor between a rectangle and a point that belongs to a tilted plane by the angle $\varphi$. Source: authors.

\subsection{The Projected Solid Angle Principle}

The former calculations allow us to find configuration factors that consist of geometric parameters or proportions. Thus, it seems reasonable that the desired values can also be determined through graphic procedures like those employed in geometry. In science, something that may sound reasonable is not always easy to prove but after some time researching we could arrive at the proper demonstrations. 
The advantages for architects and researchers are obvious compared with formulas because if during the calculations doubts appear due to the difficulty of the lighting problem, this mathematical model provides fast and easy visualization and it is suitable for BIM protocols.

In order to obtain the flux transfer between a surface and a point, we could simply draw a cone whose vertex is the study-point and its base the surface. The intersection of the said cone with a sphere of unit radius $(r=1)$ is then projected onto the reference plane (horizontal, vertical, etc.). The area inside this projection, divided by the projected area of the whole sphere on the same plane (i.e., $\pi$ ), gives the value of the configuration factors much in the same way as with the analytical methods already described (Figure 9) [30].

To summarize, view factors are dimensionless quantities or ratios that we can expressed as a relation of areas. The first area is a projection and the second is the total surface area expressed in circular terms $\pi$.

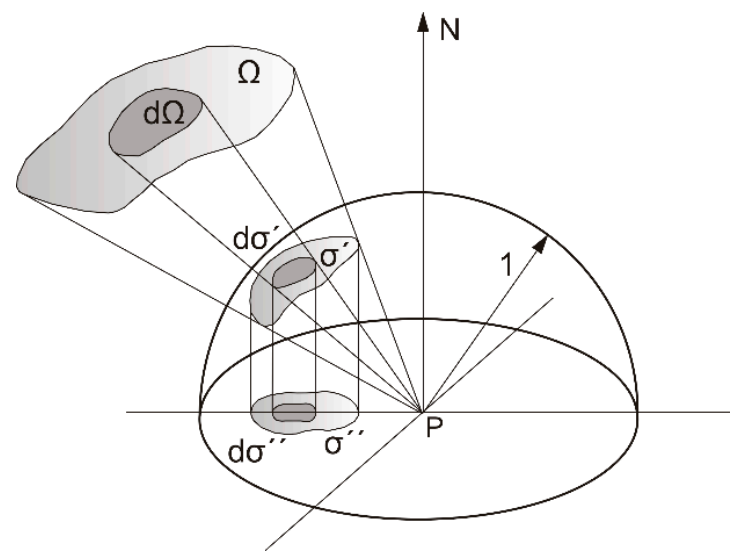

Figure 9. The light-cone in this figure cuts the area $\sigma^{\prime}$ from the unit sphere. Orthogonal projection of $\sigma^{\prime}$ onto the illuminated or irradiated plane gives the area $\sigma^{\prime \prime}$, this surface divided by $\pi r^{2}=\pi$ equates the value of the configuration factor. Source: authors.

The main consequence that we can draw from this fact is that the problem of finding the configuration factor will have a unique solution regardless of its complexity because the area of a projection always produces a definite value.

Moreover, the factors can be understood as projections and thus they possess the additive property, only recently we have defined the scalar product of configuration factors (see above). Addition is useful when dealing with several light sources, if we can add their effects or under special conditions multiply them. The average of this geometric proportion extended over the corresponding surface equates the configuration factor, which in some cases it is non-trivial to find with analytical expressions, due to calculus constraints.

The useful corollary is that we can alternately use graphic or analytical methods. In either way, we assume that we are able to solve one of the fundamental problems in radiative transfer by means of geometric procedures. This signifies that the geometric form is very important in this type of problem and not all building shapes may receive the same performance from a radiation standpoint.

In this regard, the centralized plan of Saint Louis' church contributes to increase the radiative transfers between the interior surfaces. This type of geometry with axial symmetry generates greater configuration factors than a parallelepiped surface. Theretofore, higher daylighting levels are obtained with the same reduced proportion of windows to total surface area.

\subsection{Internal Reflections}

We have dealt with the question of primary or direct radiative transfer but in order to solve the problem completely, we have to consider secondary energy sources produced by reflections that may hold fair significance in some particular cases such as in this church. In a closed space, the main 
components of secondary transfer are those produced by the limiting surfaces that, depending on their properties, re-emit some of the light that reaches them. This phenomenon may be treated with the help of a procedure similar to the so-called "radiosity" (or balancing infinite rebounds) in the technical literature, see below $[28,29]$.

Within the process of analysis of an architectural space, it is important to qualify adequately this component of inter-reflections because direct light may not be satisfactory or even wanted and secondary sources may add the required surplus to compensate for such decrement.

All cultures have been aware of the phenomena of reflection at some point or another in their history and they have furnished the interior renderings of their buildings to produce more brightness and to serve better their spatial purposes and dwelling aims. In that way, their chambers consistently enjoyed the boons of nature.

In the case of Saint Louis, the inner surfaces present a lavish decoration enriched by innumerable artworks, including, gilt pads, mirrors, engravings and frescoes. Beyond the liturgical symbolism of these decorations underlies a univocal aim to enhance illumination of the space. Such "enlightenment" undoubtedly refers to spiritual and territorial domains other than the European. Oriental and American pre-Hispanic cultures accrue in the forge of the transition to a baroque era, as we have shown, a period very much informed by the Jesuits as the present authors have studied in other treatises [31].

Particularly, some of the most significant events of the Jesuit mission in Japan feature in this church. Saint Xavier appears in his arrival to the shores of Kagoshima (Kyushu, Japan) in a niche with numerous mirrors, precious stones and other glistening devices. Moreover, presiding the altarpiece of Saint Stanislaus Kotska in the south wall, there is a representation of the three martyrs of Japan (Pablo Miki, Juan Soan de Goto and Diego Kisai) holding palms and embracing the Cross symbol of their faith and torment (Figure 10). Naturally, news of the great martyrdom of Nagasaki soon diffused in Spain. Most of the missionaries who travelled to the Asia departed from the ports of Seville and the maritime city of Cadiz. A rather curious phenomenon related with the former is that the medallion representing the three martyrs of Japan always remains in backlight.

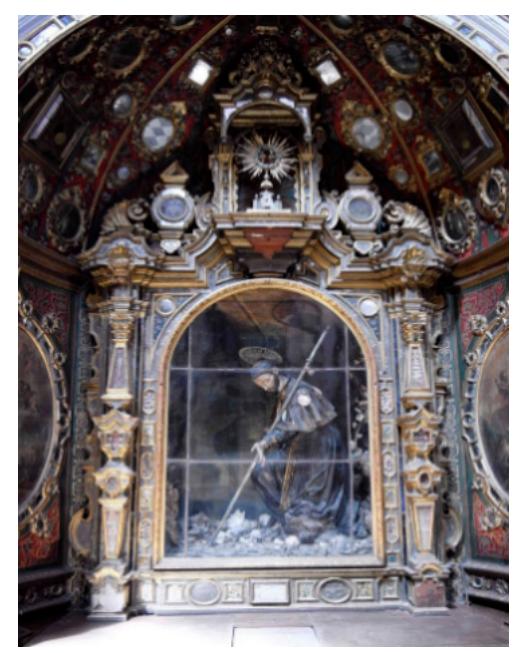

(a)

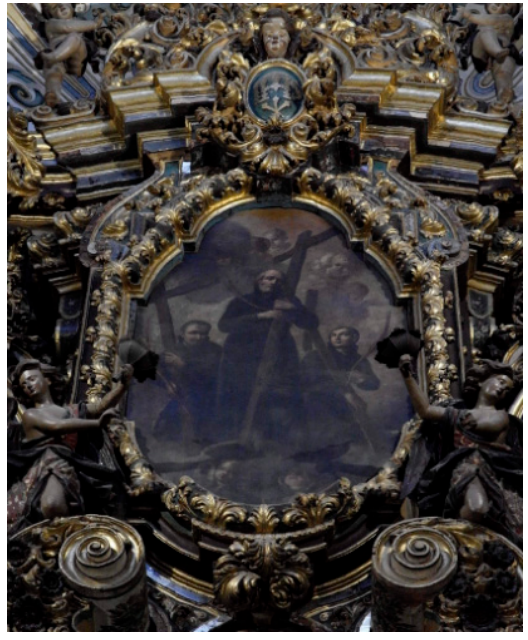

(b)

Figure 10. Interior of Saint Louis of the Frenchmen: (a) niche of St. Xavier; (b) representation of the three martyrs of Japan. Source: Almodovar-Melendo.

Returning to technical matters in discussion, we have made a summary of the necessary algebra to treat this complex problem. In the first stage, we have considered the illuminance of each surface as a final average, acquired after a high number of reflections (Figure 11). As we mentioned earlier, this procedure is akin to the procedure of balancing infinite rebounds of radiation in an enclosed volume and is amply used for thermal problems though not so often in lighting, where more detailed distributions of energy may be required. 


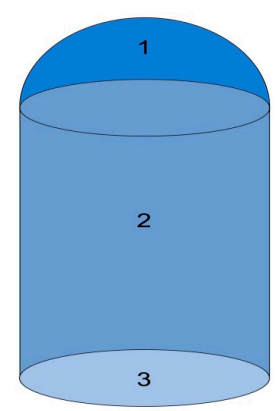

Figure 11. Typical volume of the central space in churches composed of a cylinder and a spherical cap used to find the reflected component in illuminance exchanges. Source: Cabeza-Laïnez.

For a given set of surfaces as defined in the figure above, the involved mathematics summarizes as follows: the total component is made of the direct light plus the reflected light.

$$
E_{t o t}=E_{d i r}+E_{r e f}
$$

Thus, if we are able to create two matrices $F_{d}$ and $F_{r}$ with the elements described as follows:

$$
\begin{gathered}
F_{r}=\left[\begin{array}{ccc}
1 & -F_{12} \rho_{2} & -F_{13} \rho_{3} \\
-F_{21} \rho_{1} & 1 & -F_{23} \rho_{3} \\
-F_{31} \rho_{1} & -F_{32} \rho_{2} & 1
\end{array}\right], \\
F_{r}=\left[\begin{array}{lll}
F_{11} \rho_{1} & F_{12} \rho_{2} & F_{13} \rho_{3} \\
F_{21} \rho_{1} & F_{22} \rho_{2} & F_{23} \rho_{3} \\
F_{31} \rho_{1} & F_{32} \rho_{2} & 0
\end{array}\right],
\end{gathered}
$$

On the understanding that surface 3 represents the floor plane. $F_{i j}$ are the corresponding configuration factors from surface $i$ to surface $j$ and $\rho_{i}$ is the coefficient of reflection of surface $i$.

Then we could easily establish a relationship between reflected and direct illuminance.

$$
F_{r} E_{r}=F_{d} E_{d}
$$

For instance, the first line of the matrix product above gives:

$$
E_{r 1}-E_{r 2} F_{12} F \rho_{2}-E_{r 3} F_{13} \rho_{3}=E_{d 1} F_{11} \rho_{1}+E_{d 2} F_{12} \rho_{2}+E_{d 3} F_{13} \rho_{3},
$$

And extracting the reflected component at surface 1, we would obtain,

$$
E_{r 1}=\rho_{1} F_{11} E_{d 1}-\rho_{2} F_{12}\left(E_{d 2}+E_{r 2}\right)+\rho_{3} F_{13}\left(E_{d 3}+E_{r 3}\right),
$$

Expressed in worlds the former means that, the light reflected on surface 1 is the total received from surfaces 1, 2 and 3 multiplied by their reflection coefficients and their configuration factors (in the case of 1 being curved we would deal with $F_{11}$, an auto-factor). As we have seen that total light is the sum of direct and reflected light or once again,

$$
\begin{gathered}
F^{-1}{ }_{r} F_{r} E_{r}=F^{-1}{ }_{r} F_{d} F_{d}, \\
E_{r}=F_{r d} E_{d} ; \text { where } F_{r d}=F^{-1}{ }_{r} F_{d},
\end{gathered}
$$

In this situation, the resultant component of illuminance is a sum of a direct component and a reflected one. That is, the amount of light, which a particular surface receives from the primary source and a second component consisting of the reflections, received from all the other surfaces in unison. In this way, the problem is solved from a mathematical point of view. 
Thus, if we know the direct illuminance for each surface we are able to predict all possible reflections and add them to the first one.

The reflective coefficients are often difficult to find in ancient veneers. In some cases, we had to determine them at our laboratory by constructing several replicas of the wall materials and measuring it by means of spectroscopic procedures.

Such coefficients were checked in situ whenever possible by direct monitoring (bearing in mind that the church has been closed and restored for ten years). The richer decorations correspond with the lower part of the church and do not add much quantitatively to the illumination of the space, their effect is mainly qualitative and so to say subjective.

In addition, it is interesting to notice that, the former expressions discussed, give the average value of illuminance for the whole surface (the entire drum of the church for instance), thus minimizing errors.

In the unlikely event that we would need to know a point-by-point field distribution, minor adjustments would be required for each case or usually we could divide the problem into an adequate number of sub-surfaces.

\subsection{Sky Model}

We should employ direct measurements if available from the meteorological institute, which we have proved fare well with the algorithm proposed by Pierpoint et al. [32] to obtain daylighting intensities for vertical and horizontal surfaces depending on the latitude of the place. Such clear sky-model regulates the vertical component of illuminance (in lux) as a function of the solar altitude $(\alpha)$ and the azimuth $(\beta)$, by virtue of the equation below.

$$
E_{v}=4000 \alpha^{1.3}+12,000 \sin ^{0.3} \alpha \cos ^{1.3} \alpha\left[\frac{2+\cos \beta}{3-\cos \beta}\right],
$$

If we have to deal with the CIE standard overcast sky, the former equation simplifies to:

$$
E_{v}=8500 \sin \alpha,
$$

\section{Monitoring}

In parallel, the authors have conducted a thorough monitoring campaign to modulate the range of the simulations and at the same time to check the usefulness of their outputs. We have to outline that the objective validation of our simulation program has taken place beforehand in other controlled experiments and test chambers [12-23].

To perform the evaluation, we installed data loggers in Saint Louis to monitor the dry bulb temperature, mean radiant temperature and relative humidity. The sensors were Onset models U12-012, UX 120-006 M and TMC6-HD, with data recorded every ten minutes. Temperature sensors had a measuring range from 0 to $+100{ }^{\circ} \mathrm{C}$ and an accuracy of $\pm 0.5^{\circ} \mathrm{C}$. The calibration before taking the measurements guaranteed the proper functionality of the setup.

Accumulative measures of light are not helpful from a spatial point of view, one-time measurements conducted simultaneously at a ground-floor grid work usually better. To that end, we have used a lux-meter PCE-170A with ISO calibration, a measuring range from 0 to 40,000 lux and an accuracy of $\pm 0.3 \%$. Of those, we present a comparison with simulated values for partly cloudy sky, which correspond well by not showing relevant discrepancies (Figures 12 and 13). The correlation coefficient of east-west and north-south main axis are 0.93 and 0.92 , respectively.

The slight differences registered between simulated and measured data are presumably due to the event that on the days of performance of the experiments, as the sky was partly cloudy, some sunlight filtered from the southern fenestration increasing the levels on the north niche (bottom side in the graph). Besides, the main façade of the church faces east and through the upper choir perceptible intensities appear around midday but these were deliberately taken out of the simulation. The latter would explain minor augments of level near the entrance area to the east (left side of the figure). 


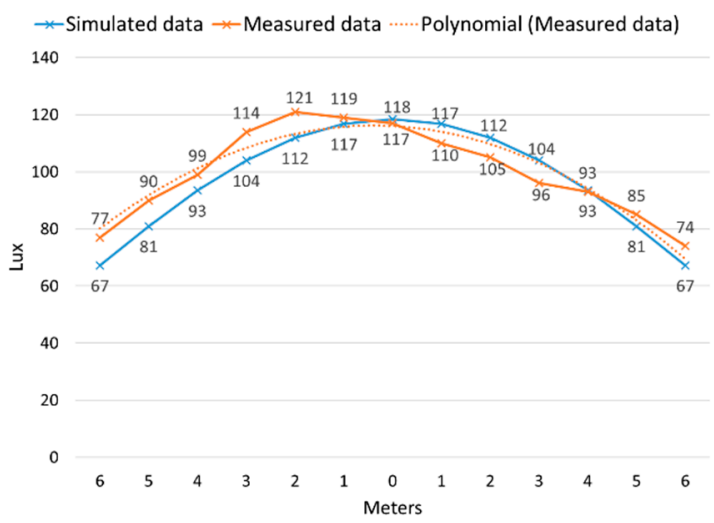

(a)

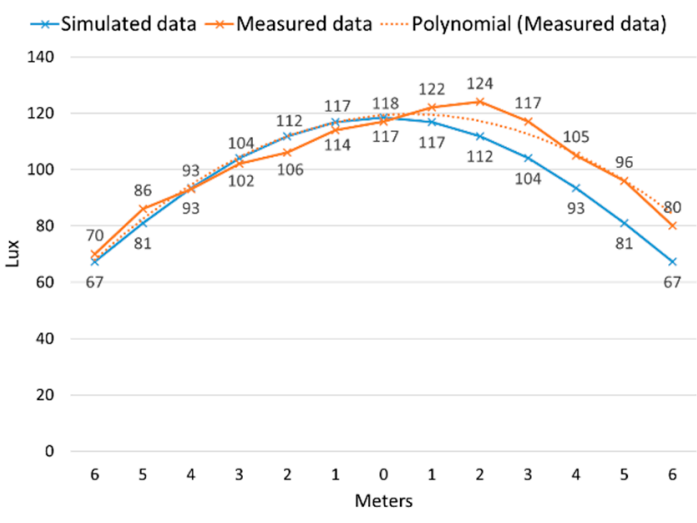

(b)

Figure 12. Comparison of measured and simulated data for partly cloudy sky at midday on 21 December. $0 \mathrm{~m}$ corresponds to the central point of the church: (a) east-west axis, from entrance (left) to the altar (right). (b) south-north axis, from right to left respectively. Source: Almodovar-Melendo.

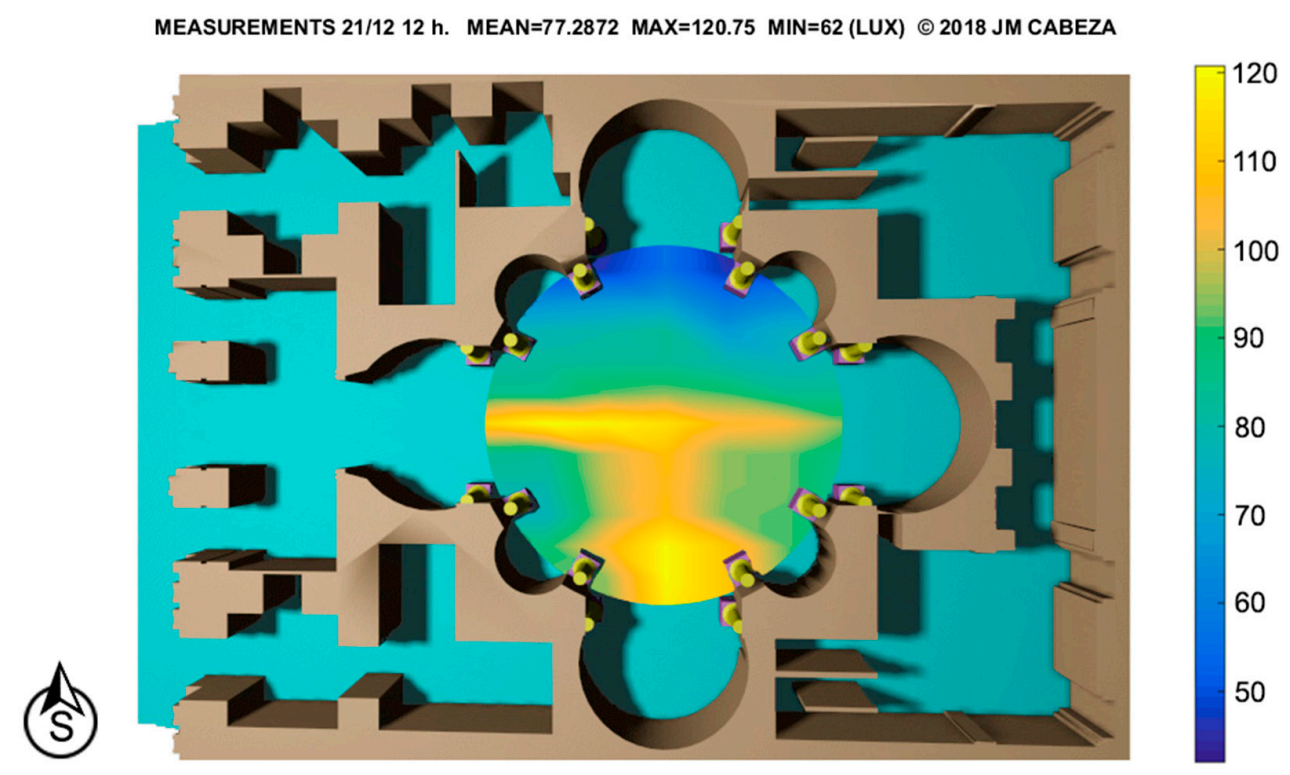

Figure 13. Extension of Figure 12, measurements effected at the ground floor in winter solstice at $12 \mathrm{~h}$. Source: Cabeza-Laïnez.

We investigated other sky plus sun conditions with occasional registers, these showing the reliability of the simulations. As stated above, the model has been validated in previous campaigns of projects with straight parallelepiped shapes in laboratory-like conditions and for that reasons we are not in the position here to offer a full-range validation for such unusual architecture, as is this church.

In order to discuss the environmental performance of the building, measured daylighting values have been correlated to other environmental parameters such as temperature and relative humidity, relevant for the IEQ of the building $[33,34]$. Measurement data registered during the summer show that the lighting values are in a range of 200 to 400 lux, by all standards a steady level of lighting apt for the majority of visual tasks. On the other hand, we identified consistent temperatures nearing $25^{\circ} \mathrm{C}$ in the floor level of the nave, at a time in which external shade temperature can reach $45^{\circ} \mathrm{C}$ or even more on the north face of the cylindrical drum (Figure 14). This means that such adequate illumination is not attained by means of discomfort or excessive overheating, as is the case of so many contemporary buildings, fully glazed. Shading devices are generally not required in this kind of structure. However, we found photographs of late 1920s in which the tall windows were shaded from the inside with 
fabrics, a curiosity which may attest to the significant amount of light that impinges on the lower levels of the compound.

Theretofore, the property of the capacitive mass of this masonry and tile (ceramics) building is noticeable. Moreover, the low ratio of window to total surface area (under $10 \%$ as previously mentioned) averts excessive solar gains and contributes to obtain an optimal thermal performance. In this regard, we have to remind that daylight is the lighting source with the best light to heat ratio (up to 160 lumen/W).

The indoor relative humidity remained around 50\% during the daily cycle though it could increase slightly at night.

Similar monitoring results were obtained by the authors at another baroque paradigm, the church of San Lorenzo in Turin (Italy) by Guarino Guarini (Figure 15). However, this temple is located almost 10 degrees more to the north than Saint Louis and markedly receives less solar radiation.

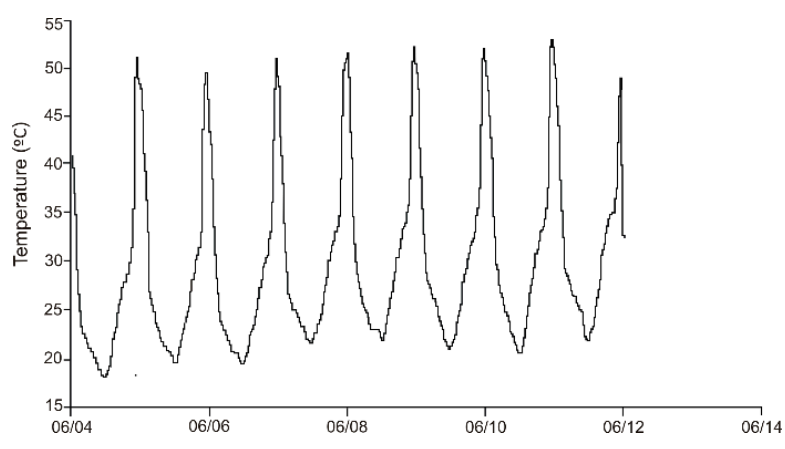

(a)

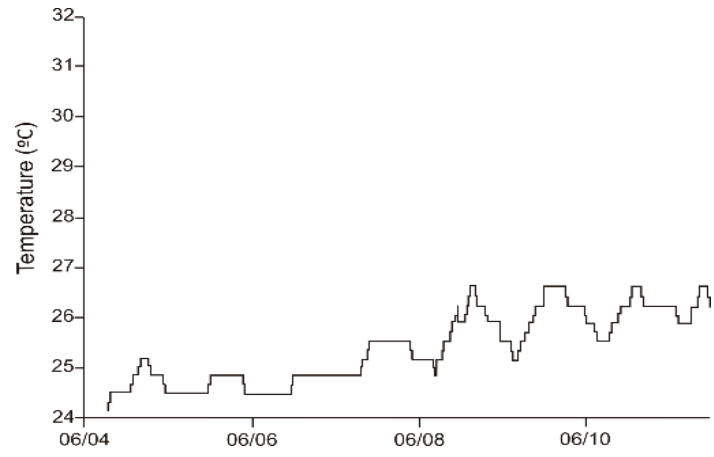

(b)

Figure 14. Temperature measured at the Church in summer to check overheating effects: (a) external temperature at the dome, (b) internal temperature at floor level near the altar. Notice that when external temperature in the north face of the drum reaches a scorching $50^{\circ} \mathrm{C}$, at the altar zone we measured a much cooler maximum of $26^{\circ} \mathrm{C}$. Source: authors.

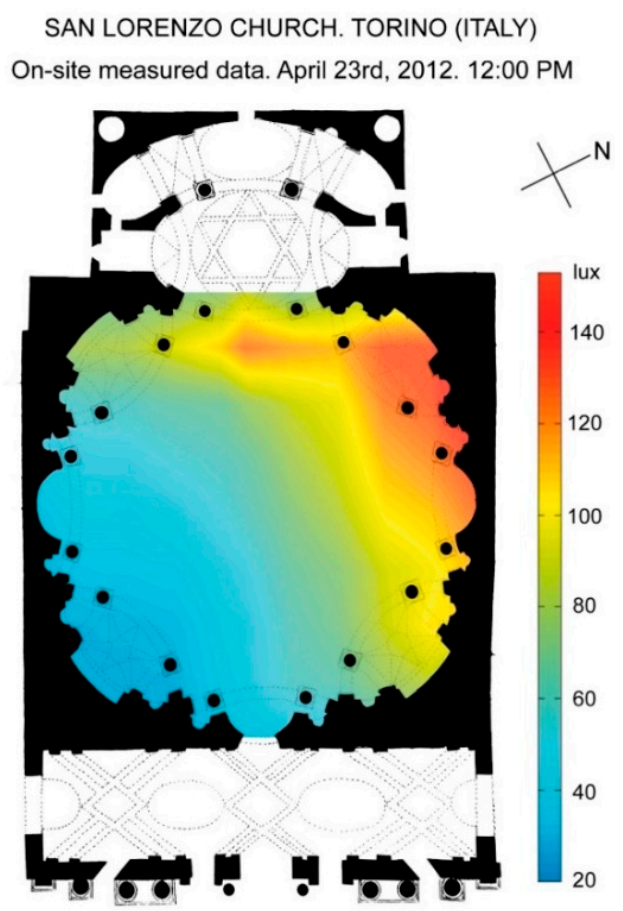

Figure 15. Clear Sky monitoring in April at the famous church by C. G. Guarini. Turin. Lat. $45^{\circ} 6^{\prime} \mathrm{N}$. Source: Cabeza-Laïnez. 


\section{Discussion of the Results}

Due to the particular orientation of the church that defies the postulate of the longitudinal West-East axis from entrance to altar, which presided over European architecture until late Renaissance; the solar events like solstices and equinoxes are critical to define the performance of the central space under consideration. In fact, the fenestrated cylindrical drum allows the capture of solar radiation impinging from every solar position and suppresses the absolute necessity of offering a southern façade to achieve solar gains for natural heating and lighting, especially in winter, as was the case of Gothic architecture in England, France and Germany. The inner cylinder so to speak funnels direct solar radiation and due to its considerable height, it seldom permits the sunrays from reaching the floor level avoiding visual discomfort to the visitors.

In each case, we have investigated two situations: overcast conditions (isotropic but with hourly and monthly variation (Figure 16) and clear sky with sun (where orientation and hourly/monthly variations are mandatory). The first condition refers to conventional models for cold climates while the second condition is more innovative and typical of warmer regions but many simulation programs are unable to deal with it not to mention with the occurrence of curved surfaces (Figures 17-19). The daylighting levels have been calculated in a plane located $1 \mathrm{~m}$ above the floor, a position deemed for a sitting person.

Spectroscopy analyses were necessary to evaluate the reflective coefficients for this simulation. To this aim the authors conducted several on site tests. Such values tend to differ from those suggested by conventional colour charts, because ageing, candle fumes or inadequate refurbishments may have altered the original condition of the veneers.

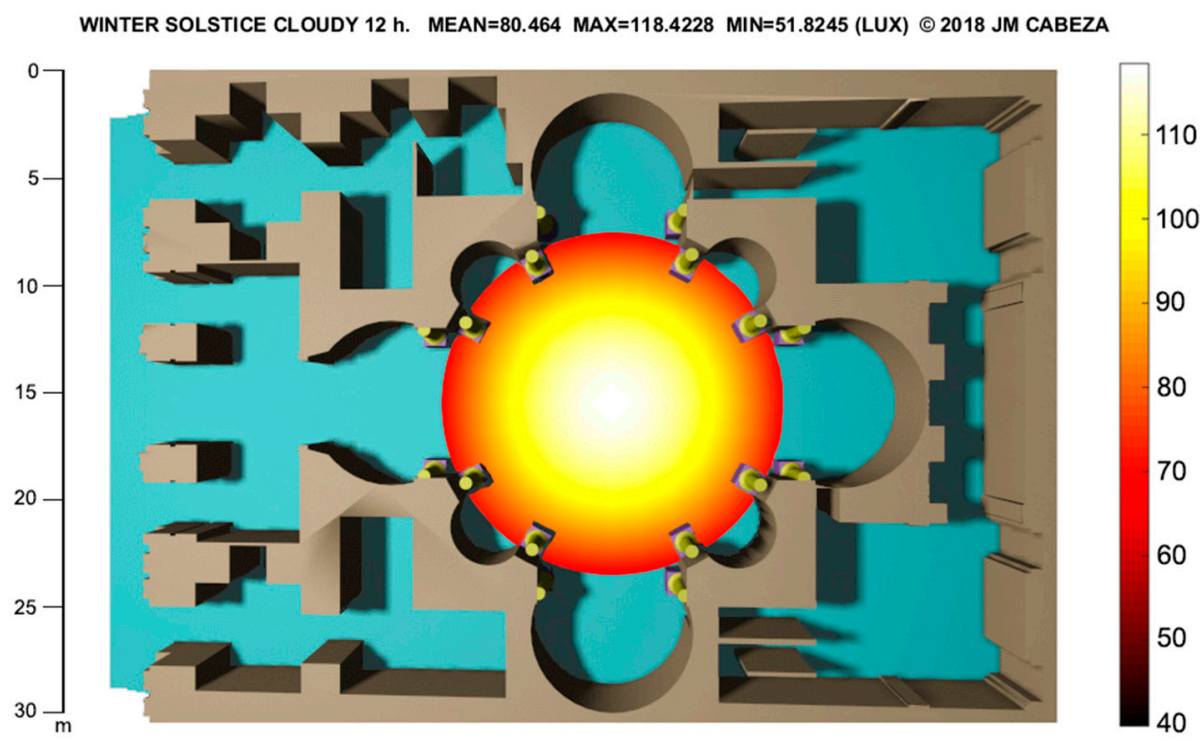

Figure 16. Cloudy Sky at midday in winter. Source: Almodovar-Melendo and Cabeza-Laïnez.

One of the most unfavourable cases occurs in winter under cloudy sky condition. Even so, the average value is more than 80 lux (Figure 16) which is considered sufficient to perform basic tasks even with modern standards. The light field is rather homogeneous (from 120 to 80 lux) in the central nave and presents a marked axial symmetry appropriate for the liturgy and reinforcement of the design intentions. The minimum levels remain well over 50 lux.

In spring, the situation is much enhanced, as even in the mornings or afternoons the mean illuminance is about 150 lux and values lying in the range from 200 to 300 lux are easily reached (Figure 17). At noon (Figure 18) the average level is over 200 lux and a maximum of circa 1000 lux can be found in several points, the light is more varied but without abrupt contrasts in a soft progression from 200 to 500 lux towards the north niche where the sun impinges during the equinox. 
The cloudy sky condition is slightly lower in its intensities but we have not presented that here since it is untypical of Seville in spring and autumn, its probability of occurrence is of $18 \%$ according to meteorological data; even so minimum values remain over 50 lux.

In summer, the mean illuminance lies in the range of 150 lux in early morning and late afternoon (Figure 19) and reaches 250 lux at noon.

If, following with the discussion on the simulations, we refer below to the vertical component of the radiation vector; the simulations show an interesting performance of light in the more likely event in Seville of enjoying a clear sky with direct sun (Figure 20). According to a TMY (typical meteorological year) of Seville provided in the software Energy Plus and derived from the Spanish Weather for Energy Calculations (SWEC), the probability of occurrence of non-clear skies in spring, autumn and summer combined is of $11 \%$.

The illumination sectional vector keeps at an angle of around 45 degrees (which means it is not too steep), this clearly allows for distinct perception of artworks and wall decorations unlike Roman pantheon and derived churches like San Bernardo alle Terme (built under the dome of an ancient thermal bath).

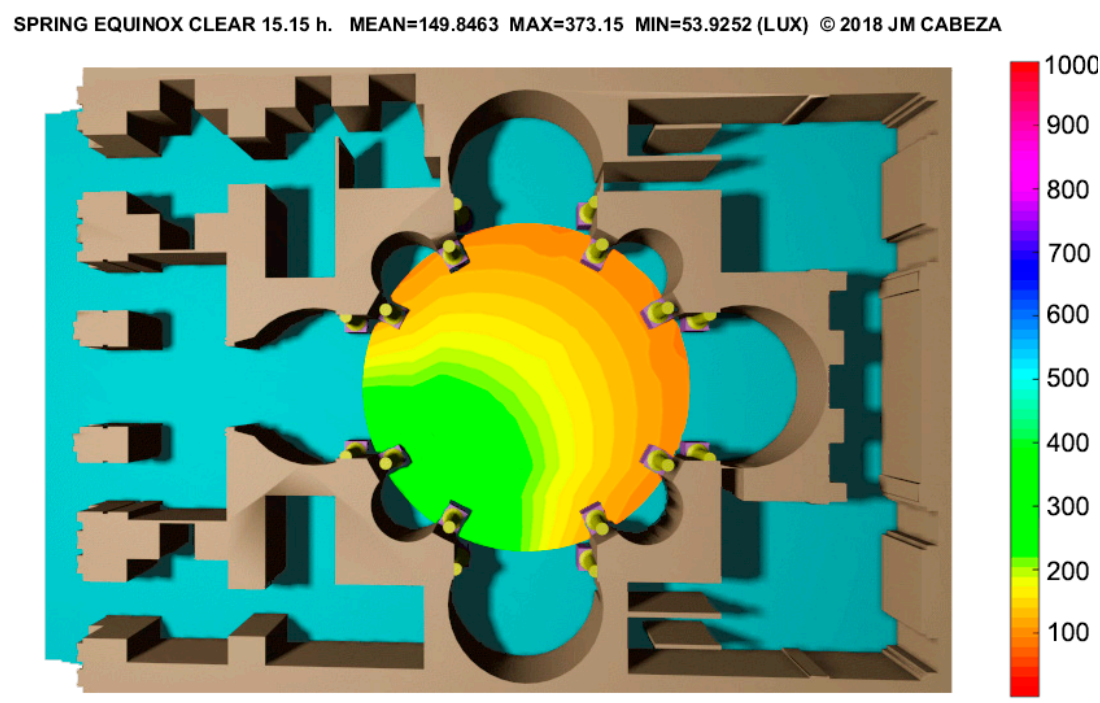

Figure 17. Spring clear sky with sun. Probability of $74 \%$ (76\% in autumn). The graph is symmetric at 15.15 h. Source: Almodovar-Melendo and Cabeza-Laïnez.

SPRING EQUINOX CLEAR 12 h. MEAN=216.5841 MAX=988.1233 MIN=55.4167 (LUX) ๑2018 JM CABEZA

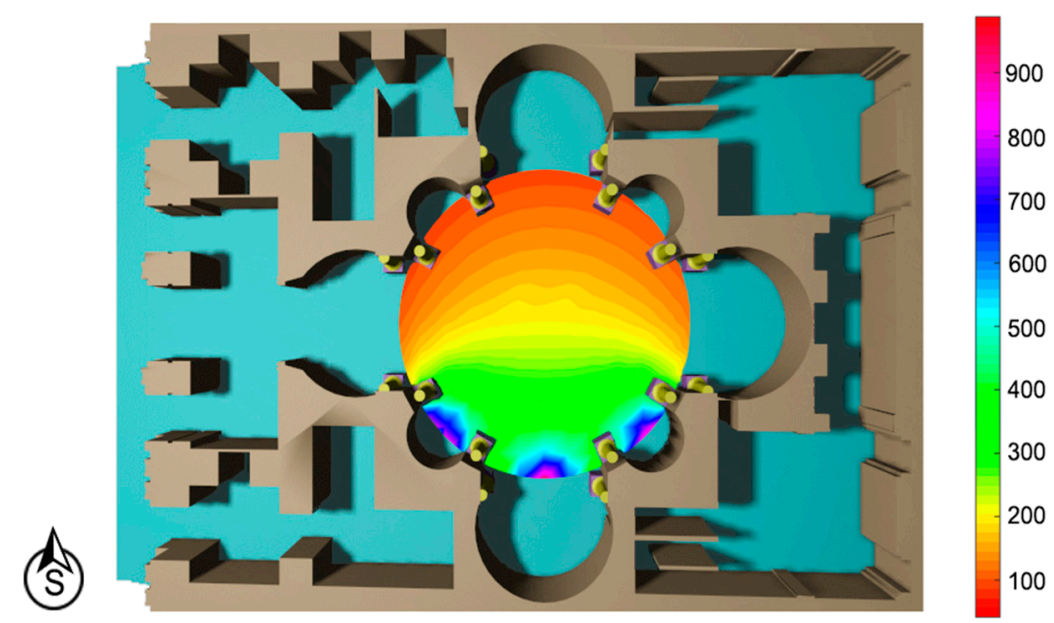

Figure 18. Spring clear sky with sun at midday, at some spots values of 1000 lux are registered. Source: Almodovar-Melendo and Cabeza-Laïnez. 


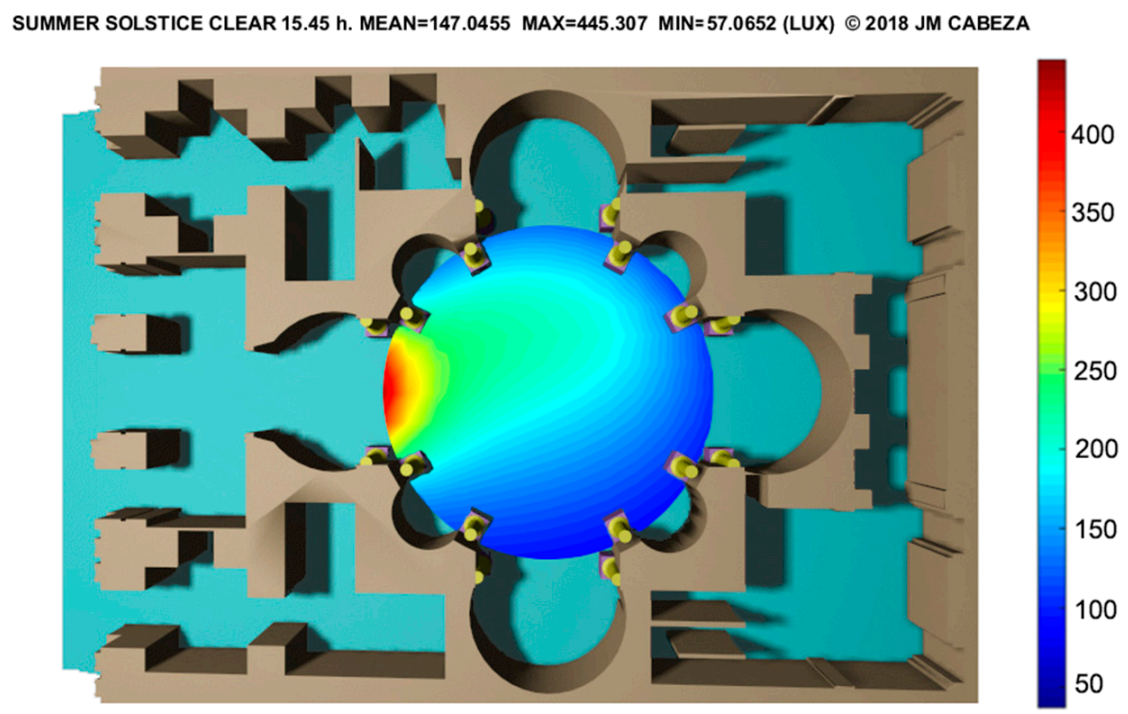

Figure 19. Summer Clear Sky with sun. Symmetric with $8.45 \mathrm{~h}$. Source: Almodovar-Melendo and Cabeza-Laïnez.

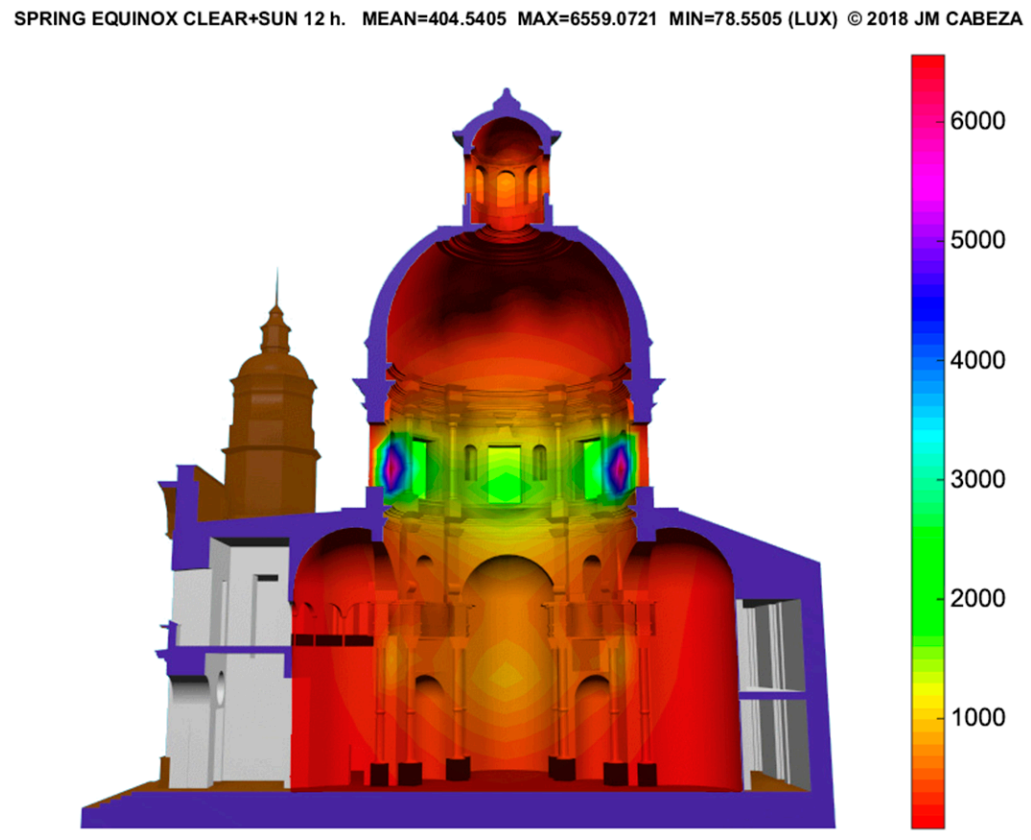

Figure 20. Daylight Section at the spring equinox with sun, midday. Values reach 300 lux at floor level. Source: Cabeza-Laïnez and Almodovar-Melendo.

Such character is less pronounced for the infrequent case of cloudy skies but can still be perceived and it has been checked against monitoring (Figure 21).

To sum up, the results examined from Figures 16-21 show that the daylighting field is balanced; with a range of around 100 lux in plan for cloudy sky in winter. In other sky conditions, values exceeding 300 lux can be amply found and over 200 lux are guaranteed in the central circle of the nave for a $56 \%$ of the total daytime. To clarify the results, we have compared in Figure 22 simulated data in Summer, Spring and Winter for clear sky with sun.

The vertical situation of lighting also facilitates orientation and perception of the space and adds variety or spark in the disposition of liturgical spaces for Southern Spain. In a famous poem (by Angel Camacho), dating from 1733 the church of Saint Louis was compared, precisely for its lighting features, to the temples of Jerusalem and Zorobadel in ancient Babylon. 


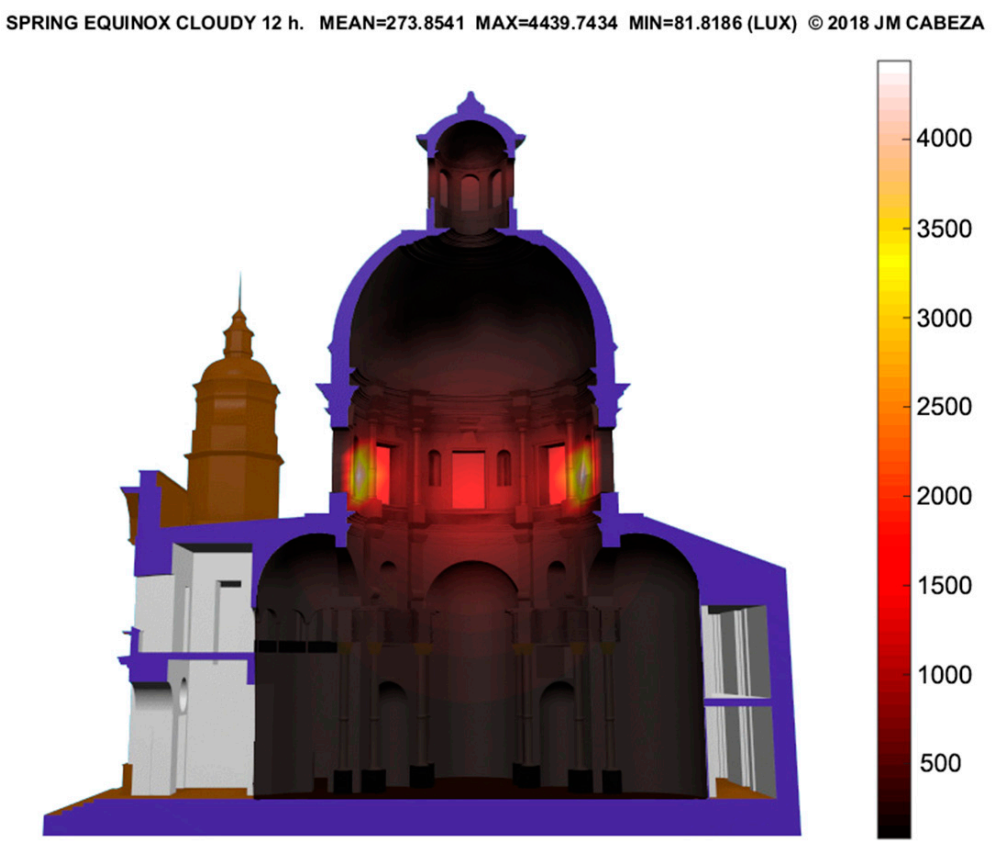

Figure 21. Daylight Section at the spring equinox in a cloudy situation. Maximum values of 200 lux on the ground. Source: Cabeza-Laïnez and Almodovar-Melendo.

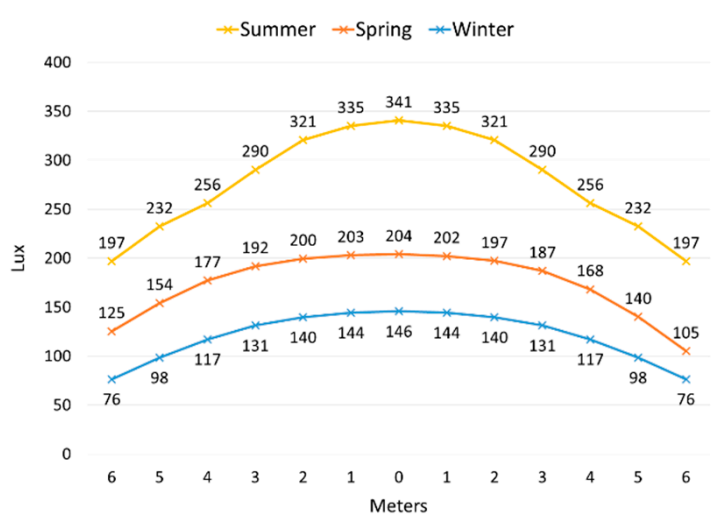

(a)

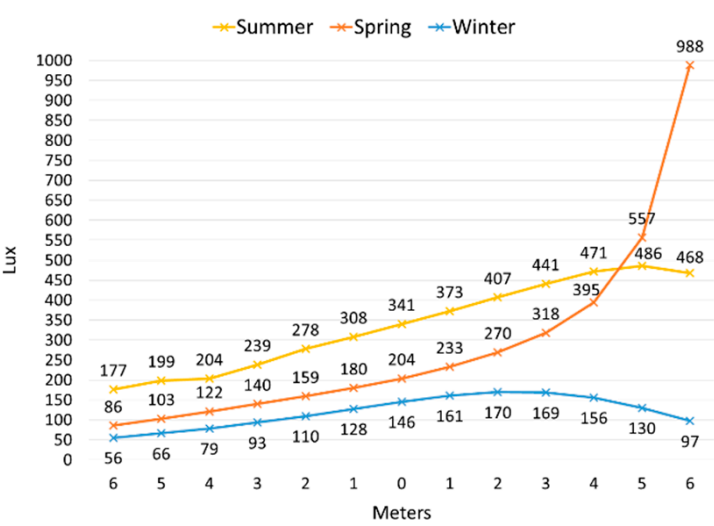

(b)

Figure 22. Comparison of simulated data for a clear sky with sun at midday: (a) east-west axis, from entrance (left) to the altar (right). (b) south-north axis, from right to left respectively. Source: Almodovar-Melendo.

Coming back on the figures to describe this considerable success of religious architecture, the small proportion of window to total surface area (less than 10\%) alongside with the low latitude of Seville $\left(37^{\circ} 22^{\prime} \mathrm{N}\right)$ may lead to such admirable results. We should notice that the values in this church are comparatively less than at its earlier baroque counterparts, which were mostly built in temperate north-central Italy and thus using wider fenestration in disregard of the heat.

Such could be the upfront explanation for the subdued illuminance levels attained on the inside of the Saint Louis temple. Especially if we compare them with some jewels of Roman Baroque (Figure 23), like Sant'Ivo by Borromini, the church at the site of ancient University of Rome and mainly Sant'Andrea by Bernini (Figure 24), an oval shaped masterpiece and not casually commissioned by the Jesuits as well.

So far, the analysis performed by the authors permit to trace a sure-handed line in the evolution of centralized temples pertaining to the baroque era. Such line is deeply chiselled in what we may call a proto-scientific artisanship of light within space. 


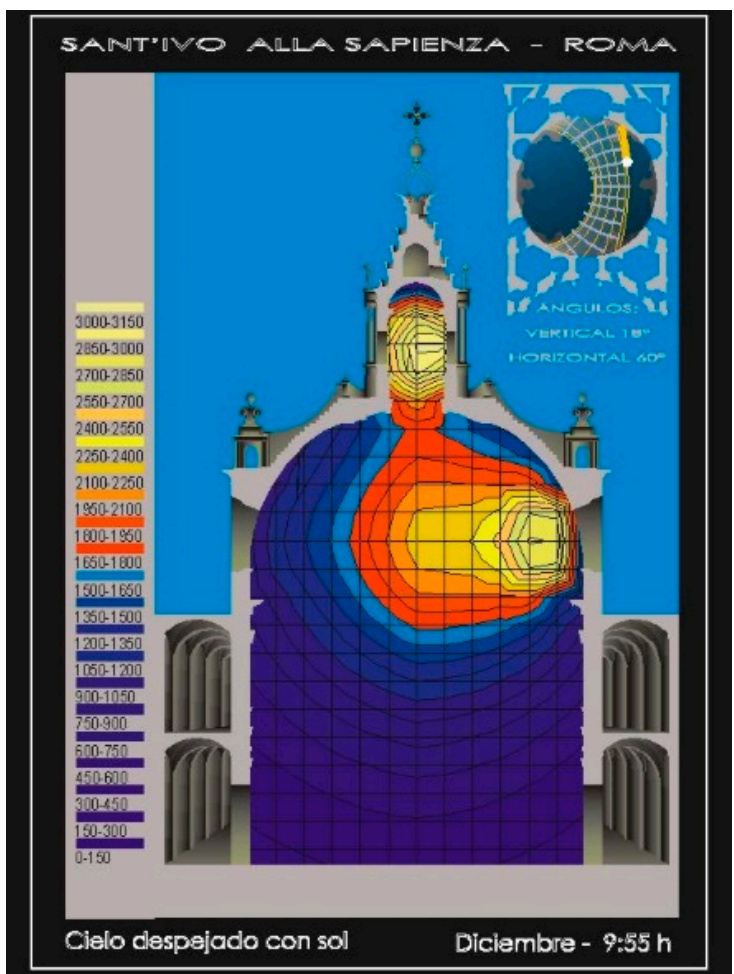

Figure 23. Simulations at Sant'Ivo by Borromini in Rome. December at 9:55 am. Clear sky plus sun. Source: Almodovar-Melendo.

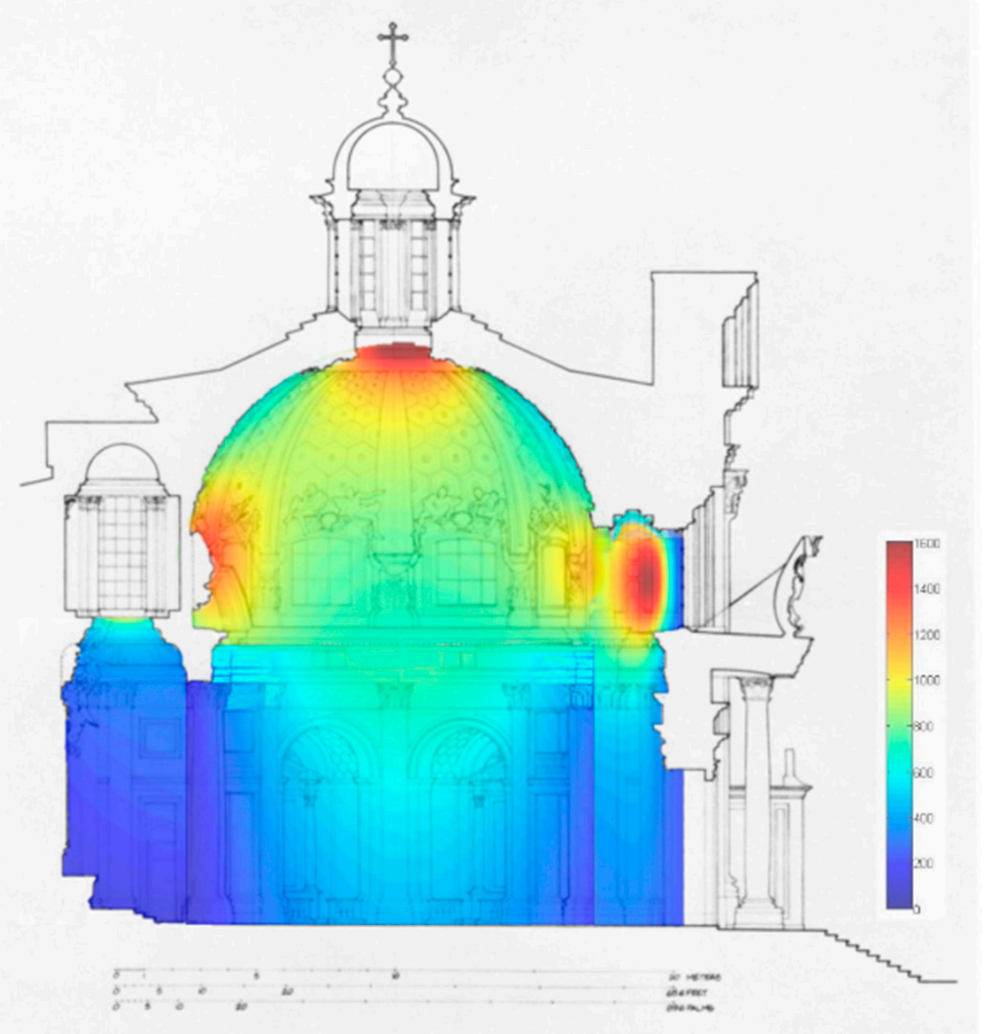

Figure 24. Simulations at Sant'Andrea by Bernini in Rome. Summer solstice. Source: Cabeza-Laïnez.

As we have clearly seen, sundry environmental and historical design strategies such as lighting, thermal comfort, et cetera, do intertwine in this analysis whilst at the same time they recall human 
and cultural nuances of architecture. For instance, the introduction of gilding and reflective specular veneers is critical in maintaining an acceptable visual perception with a restrained glazed surface. Such design features contribute to overcoming a situation perhaps created by an excessive seclusion from external climatic conditions.

Moreover, we confirm that the hypothesis by which the galleries of the nave were used as a place of study for the novices is plausible given the bright atmosphere that is achieved at the upper levels and the accuracy in which the educational and liturgical details of the interior of the dome cum drum are perceived from above.

\section{Conclusions}

In correspondence with all the former, the conservative distribution of light in the church in winter under cloudy sky starts at a dim range (around 80-100 lux) but it suffices to perform basic tasks due to its homogeneity and character as shown in the simulations and surveys. For the most part of the year, with sunny conditions, illumination is adequate though not excessive (200-400 lux) thereby avoiding overheating or solar discomfort. Thus, it leads to acceptable thermal conditions, as demonstrated by the data recorded and presented in Figures 11-14 and elsewhere. Therefore, we are reinforced in the belief that the project of this church was designed outside Spain by Father Angelo Italia, after his own experiences in a harsh warm climate in Sicily, 1699 (Figure 25).

The diverse strategies for sustainability be it thermal, luminous, acoustic and so forth, do accumulate in search of an architectural opportunity, encompassing a wealth of cultural nuances. Now and then, sustainable architecture demands an inclusive methodology to provide for the physical and aesthetic improvement of intercultural societies [35].

For instance, the whole previous analysis together with other considerations developed in the references, lead us to conclude that the Jesuit builders had been carefully summoning an ecumenical model of church. A model that could be exported outside Italy and precisely because of its environmental character, it was somewhat more encompassing for the believers of diverse cultures, be it American, Asian or African (Figure 26). Nevertheless, ignorant of the climate variations to be faced, they were unsure of the real effects of their works and consequently their success was limited outside Europe arguably for want of sustainable strategies and techniques.

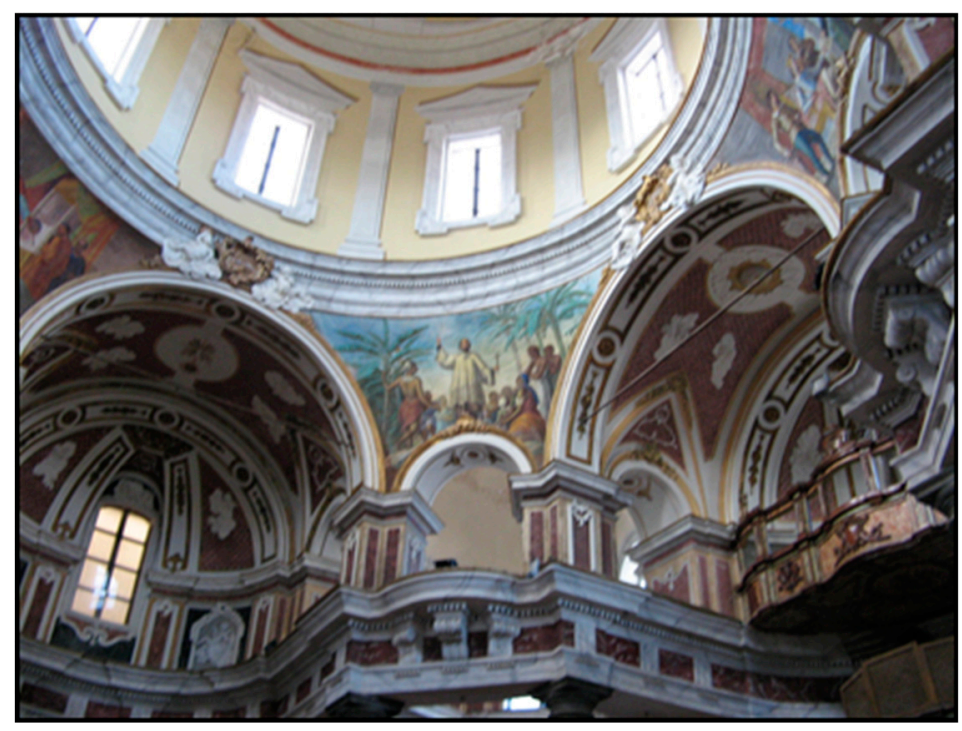

Figure 25. Summer Solstice. Interior of the Jesuit Church of San Francesco Saverio (St. Francis Xavier) in Palermo, Sicily (Italy). Source: Cabeza-Laïnez.

In this article, we continue in proving that simulation is a feasible tool for enhancing our knowledge of human architectural heritage [36], as well as in the matters of understanding the 
production and restoration of space, modulation of energy and eventually needs for supplementary artificial means (Figure 27).

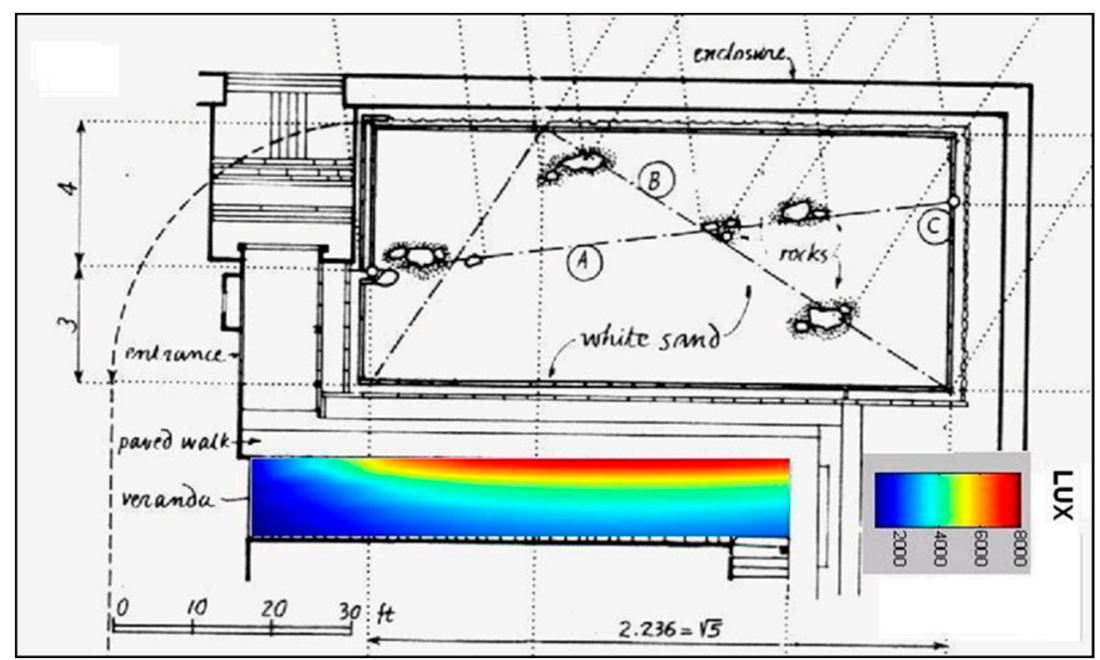

Figure 26. Summer Solstice. Simulation of reflected radiation by white sands, under the eaves of the Buddhist temple of Ryoanji in Kyoto (Japan). Values reach 10,000 lux as monitored by Joseph Cabeza-Laïnez.

Through geometrical parameters within which the subtle mathematics of configuration factors resides, we are finally able to recognize the importance of geometry related to lighting [37] and by extension to sustainability matters.

Not in vain, one of the architects hereby analysed-the sublime priest Camillo Guarino Guarini-wrote in his treatise "Euclides Adauctus et Methodicus":

"Since the magic of insuperable wondrous mathematics shines brightly on marvellous and truly regal Architecture"

(Sed insuper Thaumaturga Mathematicorum miraculorum insigne vereque Regali Architectura coruscat)

The famed quote praised the Savoyard King for his architectural wisdom but the author of the immortal Chapel of the Holy Shroud in Turin, inexplicably ruined by arson in 1998, dawned the Era of Baroque Reason.
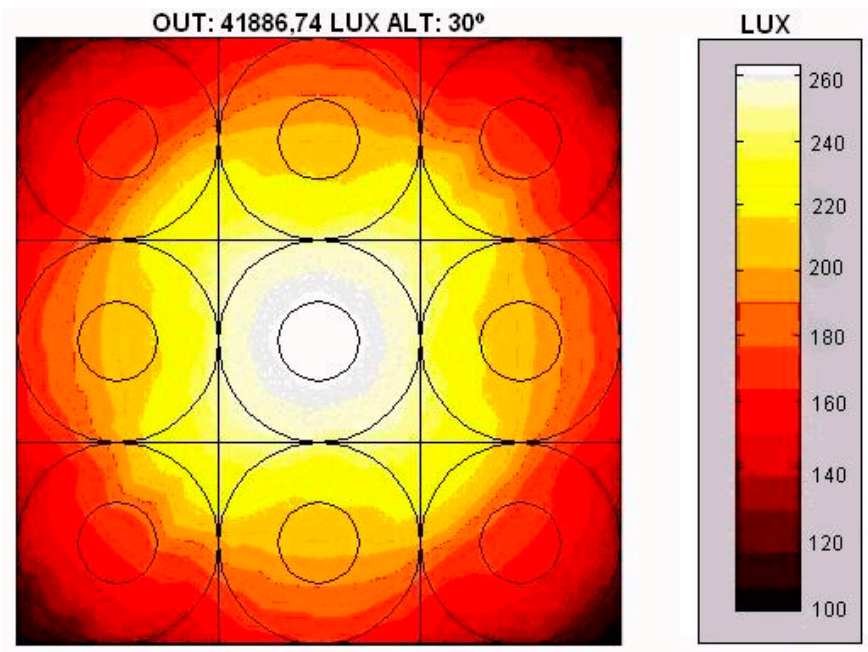

Figure 27. Simulation of an array of nine circular skylights in the Paris National Library. Clear sky with sun. Architect Henri Labrouste. Source: Cabeza-Laïnez. 
Author Contributions: Each author contributed equally to the article.

Acknowledgments: Joseph Cabeza-Laïnez and Jose M. Almodovar-Melendo are grateful for the consistent help of the following young researchers: Lorenzo Muro Álvarez, Miguel Gutiérrez Villarrubia, César Puchol Barcina, Juan Martínez Bonilla and Gonzalo Pulido López. Inmaculada Rodriguez-Cunill would like to thank the artist and conserver Eva Guil Walls as well as professor and lighting artist Begoña Gutiérrez San Miguel. The assistance of professor and art historian Paula Revenga Dominguez is deeply recognised.

Conflicts of Interest: The authors declare no conflict of interest.

\section{References}

1. Ne'eman, E. Visual Aspects of Sunlight in Buildings. Light. Res. Technol. 1974, 6, 159-164. [CrossRef]

2. Giedion, S. The Eternal Present. The Beginning of Architecture; Oxford University Press: Oxford, UK, 1964.

3. Cabeza, J.M.; Takahito, S.; Almodovar, J.M.; Jiménez, J.R. Lighting Features in Japanese Traditional Architecture. In Proceedings of the 23rd International Conference on Passive and Low Energy Architecture, Geneva, Switzerland, 6-8 September 2006; pp. 192-198.

4. Cabeza, J.M. Fundamentals of Luminous Radiative Transfer; Netbiblo: Seville, Spain, 2010. (In Spanish)

5. Almodovar, J.M.; La Roche, P. Effects of window size in daylighting and energy performance in buildings. In Proceedings of the American Solar Energy Society Annual Conference, San Diego, CA, USA, 3-8 May 2008; pp. 4345-4351.

6. Cabeza, J.M. Solar radiation in buildings, simulation and transfer procedures. In Solar Radiation; InTech: Shanghai, China, 2012; pp. 291-314.

7. Baker, N.V.; Fanchiotti, A.; Steemers, K.N. Daylighting in Architecture. A European Reference Book; Commission of the European Communities; Directorate General XII; Routledge: London, UK, 1993.

8. Yamauchi, J. Theory of Field of Illumination; No. 339; Researches of the Electro-Technical Laboratory: Tokyo, Japan, 1932.

9. Moon, P.H. The Scientific Basis of Illuminating Engineering; Dover Publications: New York, NY, USA, 1962.

10. Moon, P.H.; Spencer, D.E. The Photic Field; The MIT Press: Cambridge, MA, USA, 1981.

11. Jammer, M. Concepts of Space: The History of Theories of Space in Physics; Dover Publications: New York, NY, USA, 1993.

12. Cabeza-Lainez, J.M. The Quest for Light in Indian architectural heritage. J. Asian Archit. Build. Eng. 2008, 7, 39-46. [CrossRef]

13. Almodóvar-Melendo, J.M.; Cabeza-Lainez, J.M. Nineteen thirties architecture for tropical countries: Le Corbusier's brise-soleil at the Ministry of Education in Rio de Janeiro. J. Asian Archit. Build. Eng. 2008, 7,9-14.

14. Almodovar, J.M.; La Roche, P.; Jimenez, J.R.; Dominguez, I. Scientific design of skylights: the case of an office building in Gelves, Seville. In Proceedings of the 28th World Conference on Passive and Low Energy in Architecture, Lima, Peru, 7-9 November 2012.

15. Cabeza-Lainez, J.M.; Almodóvar-Melendo, J.M. The Japanese Experience of Environmental Architecture through the Works of Bruno Taut and Antonin Raymond. J. Asian Archit. Build. Eng. 2007, 6, 33-40. [CrossRef]

16. Cabeza-Lainez, J.M.; Almodóvar-Melendo, J.M. Architectural Simulation for Sustainability. In Proceedings of the World Sustainable Building Conference, Tokyo, Japan, 27-28 September 2005; pp. 1023-1031.

17. Cabeza-Lainez, J.M. Lighting Features in Indian-Style Traditional Architecture. In Sun Wind and Architecture, Proceedings of the 24th International Conference on Passive and Low Energy Architecture, Singapore, 22-24 November 2007; National University of Singapore: Singapore; pp. 446-4550.

18. Cabeza-Lainez, J.M. Radiative Performance of Louvres, Simulation and Examples in Asian Architecture. In Proceedings of the 6th International Conference on Indoor Air Quality, Ventilation and Energy Conservation in Buildings (IAQVEC), Sendai, Japan, 28-31 October 2007; pp. 445-452.

19. Cabeza-Lainez, J.M. Some Considerations on the Environmental Properties of Domes. In Architecture and Urban Space, Proceedings of the 6th International Conference on Passive and Low Energy Architecture, Sevilla, Spain, 24-27 September 1991; Springer: Heidelberg, Germany; pp. 541-547. 
20. Cabeza-Lainez, J.M. The Library in the Faculty of Engineering a case of Holistic Simulation. In Sustainable Communities and Architecture, Proceedings of the International Conference on Passive and Low Energy Architecture, Kushiro, Japan, 8-10 January 1997; PLEA 1997 Japan Committee: Kushiro, Japan; pp. 75-80.

21. Cabeza-Lainez, J.M.; Almodovar-Melendo, J.M. Simulation of Baroque religious Buildings. In Environmentally Friendly Cities, Proceedings of the International Conference on Passive and Low Energy Architecture, Lisboa, Portugal, 1-5 June 1998; James \& James Science Publishers Ltd.: London, UK; pp. 421-424.

22. Cabeza-Lainez, J.M. Scientific Design of Skylights. In Sustaining the Future, Energy-Ecology-Architecture, Proceedings of PLEA International Conference, Brisbane, Australia, 22-24 September 1999; PLEA International: Brisbane, Australia; pp. 541-546.

23. Cabeza-Lainez, J.M.; Almodovar-Melendo, J.M. The Quest for Daylight: Evolution of Domes in South American Baroque. In Renewable Energy for a Sustainable Development, Proceedings of the Plea 18th Conference, Florianopolis, Brazil, 7-9 November 2001; Universidade Federal de Santa Catarina: Florianópolis, Brazil; pp. 161-168.

24. Banda y Vargas, A. La Iglesia Sevillana de San Luis de los Franceses; Diputación Provincial de Sevilla: Sevilla, Spain, 1977. (In Spanish)

25. Rodriguez-Cunill, I. Painting through the eye of a camera. Comunicación Revista Internacional de Comunicación Audiovisual, Publicidad y Estudios Culturales 2003, 4, 51-65. (In Spanish)

26. Higbie, H. Lighting Calculations; John Wiley \& Sons: New York, NY, USA, 1934.

27. Lambert, J.H. Photometry, or, on the Measure and Gradations of Light, Colors and Shade; DiLaura, D.L., Translator; Illuminating Engineering Society of North America: New York, NY, USA, 2001.

28. Kittler, R.; Kocifaj, M.; Stanislav, D. Daylighting Science and Daylighting Technology; Springer: Heidelberg, Germany, 2012.

29. Ashdown, I. Radiosity: A Programmer's Perspective; John Wiley \& Sons: New York, NY, USA, 2004.

30. Fok, V.A. Zur Berechnung von Beleuchtungsstärke (On the calculations of Lighting Power); Institute of Optics, St. Petersburg University: Saint Petersburg, Russia, 1924. (In German)

31. Bailey, G.A. Art of the Jesuit Missions in Asia and Latin America, 1542-1773; University of Toronto Press: Toronto, ON, Canada, 2001.

32. Pierpoint, W. A Simple Sky Model for Daylighting Calculations. In Proceedings of the International Daylighting Conference, Phoenix, AZ, USA, 16-18 February 1983.

33. Katunský, D.; Dolníková, E.; Doroudiani, S. Integrated Lighting Efficiency Analysis in Large Industrial Buildings to Enhance Indoor Environmental Quality. Buildings 2017, 7, 47. [CrossRef]

34. Molina, F.Q.; Yaguana, D.B. Indoor Environmental Quality of Urban Residential Buildings in Cuenca-Ecuador: Comfort Standard. Buildings 2018, 8, 90. [CrossRef]

35. Almodovar-Melendo, J.M.; Cabeza-Lainez, J.M. Environmental Features of Chinese Architectural Heritage: The Standardization of Form in the Pursuit of Equilibrium with Nature. Sustainability 2018, 10, 2443. [CrossRef]

36. Mohelníková, J.; Míček, D.; Floreková, S.; Selucká, A.; Dvořák, M. Analysis of Daylight Control in a Chateau Interior. Buildings 2018, 8, 68. [CrossRef]

37. Katunský, D.; Dolníková, E.; Dolník, B. Daytime Lighting Assessment in Textile Factories Using Connected Windows in Slovakia: A Case Study. Sustainability 2018, 10, 655. [CrossRef]

(C) 2018 by the authors. Licensee MDPI, Basel, Switzerland. This article is an open access article distributed under the terms and conditions of the Creative Commons Attribution (CC BY) license (http://creativecommons.org/licenses/by/4.0/). 